\title{
Cellular and synaptic localization of EAAT2a in human cerebral cortex
}

\author{
Marcello Melone ${ }^{1}$, Michele Bellesi $^{1}$, Alessandro Ducati ${ }^{2}$, Maurizio lacoangeli ${ }^{2,3}$ and Fiorenzo Conti ${ }^{1,4 *}$ \\ 1 Department of Neuroscience, Section of Physiology, Università Politecnica delle Marche, Ancona, Italy \\ 2 Department of Neuroscience, Section of Neurosurgery, Università di Torino, Torino, Italy \\ ${ }^{3}$ Department of Neuroscience, Section of Neurosurgery, Università Politecnica delle Marche, Ancona, Italy \\ ${ }^{4}$ Fondazione di Medicina Molecolare, Università Politecnica delle Marche, Ancona, Italy
}

\section{Edited by:}

Alfonso Fairén, University Miguel

Hernandez, Spain

\section{Reviewed by:}

Masahiko Watanabe, Hokkaido

University, Japan

Carlos Matute, Universidad del País

Vasco, Spain

${ }^{*}$ Correspondence:

Fiorenzo Conti, Dipartimento di

Neuroscienze, Sezione di Fisiologia,

Università Politecnica delle Marche, Via

Tronto 10/A, Torrette di Ancona, I-60020

Ancona, Italy.

e-mail:f.conti@univpm.it
We used light and electron microscopic immunocytochemical techniques to analyze the distribution, cellular and synaptic localization of EAAT2, the main glutamate transporter, in normal human neocortex. EAAT2a-immunoreactivity (ir) was in all layers and consisted of small neuropilar puncta and rare cells. In white matter EAAT2a+ cells were numerous. Electron microscopic studies showed that in gray matter $\sim 77 \%$ of immunoreactive elements were astrocytic processes, $\sim 14 \%$ axon terminals, $\sim 2.8 \%$ dendrites, whereas $\sim 5 \%$ were unidentifiable. In white matter, $\sim 81 \%$ were astrocytic processes, $\sim 17 \%$ were myelinated axons, and $\sim 2.0 \%$ were unidentified. EAAT2a-ir was never in microglial cells and oligodendrocytes. Pre-embedding electron microscopy showed that $67 \%$ of EAAT2a expressed at (or in the vicinity of) asymmetric synapses was in astrocytes, $17 \%$ in axon terminals, while $~ 13 \%$ was both in astrocytes and in axons. Post-embedding electron microscopy studies showed that in astrocytic processes contacting asymmetric synapses and in axon terminals, gold particle density was $\sim 25.1$ and $\sim 2.8$ particles $/ \mu \mathrm{m}^{2}$, respectively, and was concentrated in a membrane region extending for $\sim 300 \mathrm{~nm}$ from the active zone edge. Besides representing the first detailed description of EAAT2a in human cerebral cortex, these findings may contribute to understanding its role in the pathophysiology of neuropsychiatric diseases.

Keywords: Glutamate transporters, EAAT2, human neocortex, immunogold post-embedding electron microscopy

\section{INTRODUCTION}

Glutamate is the major neurotransmitter in the cerebral cortex. Beyond its role in fast excitatory signaling, it is important in synaptogenesis, synaptic plasticity and in the pathophysiology of neuropsychiatric diseases (Conti and Hicks, 1996). Glutamatemediated transmission depends on highly regulated mechanisms operating at pre- and post-synaptic sites, and on mechanism responsible for rapid clearance of the transmitter at the cleft, i.e., passive diffusion, and the action of high-affinity excitatory amino acid transporters (EAATs; Conti and Weinberg, 1999). Much evidence has demonstrated that EAATs maintain physiological levels of glutamate, contribute to sculpting excitatory post-synaptic currents and modulating glutamate diffusion (Conti and Weinberg, 1999; Rusakov et al., 1999; Danbolt, 2001; Torres and Amara, 2007; Tzingounis and Wadiche, 2007).

Five EAATs have been characterized in the mammalian central nervous system: EAAT1 (GLAST; SLC1A3), EAAT2 (GLT-1; SLC1A2), EAAT3 (EAAC1; SLC1A1), EAAT4 (SLC1A6), and EAAT5 (SLC1A7); of these, EAAT2 exhibits the highest level of expression, is responsible for the largest proportion of total glutamate transport and its functional inactivation raises extracellular glutamate to toxic levels (Rothstein et al., 1996; Tanaka et al., 1997; Conti and Weinberg, 1999; Rusakov et al., 1999; Danbolt, 2001; Kanai and Hediger, 2004; Torres and Amara, 2007; Tzingounis and Wadiche, 2007). In both rodents and humans, three functional EAAT2 isoforms, named EAAT2a-c, have been reported (Lauriat and McInnes, 2007); EAAT2a (the protein originally called EAAT2) is more abundant and more closely related to synapses than the other isoforms (Lauriat and McInnes, 2007). In rodents, EAAT2a is expressed by astrocytes (Danbolt et al., 1992; Levy et al., 1993; Rothstein et al., 1994; Torp et al., 1994; Lehre et al., 1995; Minelli et al., 2001; Melone et al., 2009; de Vivo et al., 2010), and, albeit at lower levels, by neurons (Chen et al., 2004; Furness et al., 2008; Holmseth et al., 2009; Melone et al., 2009; see also Berger et al., 2005; and de Vivo et al., 2010). In both astrocytic processes and axon terminals, most EAAT2a is perisynaptic, i.e., in the plasma membrane region extending $200-250 \mathrm{~nm}$ from the edge of the active zone (Melone et al., 2009), a position suitable for modulating Glu concentration in the cleft. Recently, we showed that enhancing transcription of GLT-1 gene increases the density of gold particles coding for EAAT2 near and within active zones of hippocampal mossy fiber (MF) terminals and in astrocytic processes and that this effect is associated with a significant impairment of longterm depression and long-term potentiation at MF-CA3 synapses (Omrani et al., 2009). Thus, based on studies in rodents, regulation of EAAT2-mediated glutamate uptake may be important for maintaining the level of synaptic strength during long-term changes in synaptic efficacy (Katagiri et al., 2001; Levenson et al., 2002; Omrani et al., 2009).

EAAT2 has been associated with the pathophysiology of several neuropsychiatric diseases, including amyotrophic lateral sclerosis, Alzheimer's disease, schizophrenia, Huntington's disease, epilepsy, 
cerebral ischemia, and multiple sclerosis (Beart and O'Shea, 2007; Lauriat and McInnes, 2007; Sheldon and Robinson, 2007; Rothstein, 2009). How EAAT2 contributes to the pathophysiology of these diseases is at present unclear. In some, perhaps most, cases, an excitotoxic mechanism is probable, but in others it appears that the contribution of EAAT2 dysfunction is more likely to induce changes in synaptic physiology. One necessary prerequisite to shed some light on the pathophysiological role(s) of EAAT2 is to have firm data on its localization in human cortex. To date, EAAT2 has been described only cursorily in human cerebral cortex (see Discussion) and very little is known on its distribution and, most importantly, on its cellular and synaptic localization. Given this scenario, we used immunocytochemical light and electron microscopy to investigate the cellular and synaptic localization of EAAT2 $\mathrm{a}$ in a collection of bioptic samples of human association cortices.

\section{MATERIALS AND METHODS TISSUE PREPARATION}

Human cortical tissue was obtained from surgical specimens of 13 adult patients with brain tumors and of 1 with an hemorrhagic stroke; clinical data are summarized in Table 1. Samples from 7 of the 13 cases have been used previously (Conti et al., 1998, 1999; Melone et al., 2004, 2005a, 2006). Cortical tissue used in this study was not located in the vicinity of the tumor: it was macroscopically normal tissue that had to be resected in order to reach deep-seated tumors or was included in "tactical lobectomies," and showed no signs of edema. None of the patients suffered form pre- or postoperative seizures. Informed consent to the surgical procedure was obtained in all cases. The approximate location of samples is shown in Figure 1.
Specimens used for immunocytochemistry (ICC) were quickly (2-3 min) immersed in a cold solution of 4\% paraformaldehyde (PFA) in $0.1 \mathrm{M}$ phosphate buffer (PB) for $2-3 \mathrm{~h}$ and then transferred to a fresh solution of $4 \%$ PFA $\left(24-48 \mathrm{~h}\right.$ at $\left.4^{\circ} \mathrm{C}\right)$. Samples were cut into small blocks that were further post-fixed $\left(24-72 \mathrm{~h}\right.$ at $4^{\circ} \mathrm{C}$ in the same solution), washed several times with $\mathrm{PB}$ and stored at $-20{ }^{\circ} \mathrm{C}$ in a solution containing $30 \%$ glycerol, $30 \%$ ethylene glycol, $30 \%$ distilled water and 10\% PB 0.4 M. Before cutting, blocks were washed several times in $\mathrm{PB}$, cut on a Vibratome into 30-35 $\mu \mathrm{m}$ thick sections, and collected in groups of 10; of these, 1 was stained with $0.1 \%$ thionine, and 9 were used for ICC.

For western blotting studies, samples were immediately immersed into ice-cold buffer ( $4 \mathrm{mM}$ Tris, $\mathrm{pH} 7.4 ; 0.32 \mathrm{M}$ sucrose; $1 \mathrm{mM}$ EDTA; $0.23 \mathrm{mM}$ dithiothreitol; and $1 \mu \mathrm{M}$ leupeptin and pepstatin A) and then homogenized with a glass-Teflon homogenizer in 6 volume of the same buffer. Synaptic membranes preparation was performed as described (Danbolt et al., 1990).

\section{ANTIBODIES}

Polyclonal antibodies directed against a synthetic peptide corresponding to the rodent and human amino acid sequence 559-573 (SADCSVEEEPWKREK; Pines et al., 1992; Arriza et al., 1994) of EAAT2a C-terminus (characterized in Rothstein et al., 1994; Chen et al., 2004) were used. In our hands, specificity of antibodies (batch \#080706) has been demonstrated by the lack of immunoreactivity in GLT-1-KO mice (Omrani et al., 2009). In the present material, specificity of EAAT2a antibodies was assessed by western blottings of synaptic membranes prepared from samples of parietal cortex, and by preadsorbing EAAT2a antibodies with $10^{-3}$ M EAAT2 $_{559-573}$ synthetic peptide in tissue (HBC 961102 and HBC 980510).

Table 1 | Summary of clinical data.

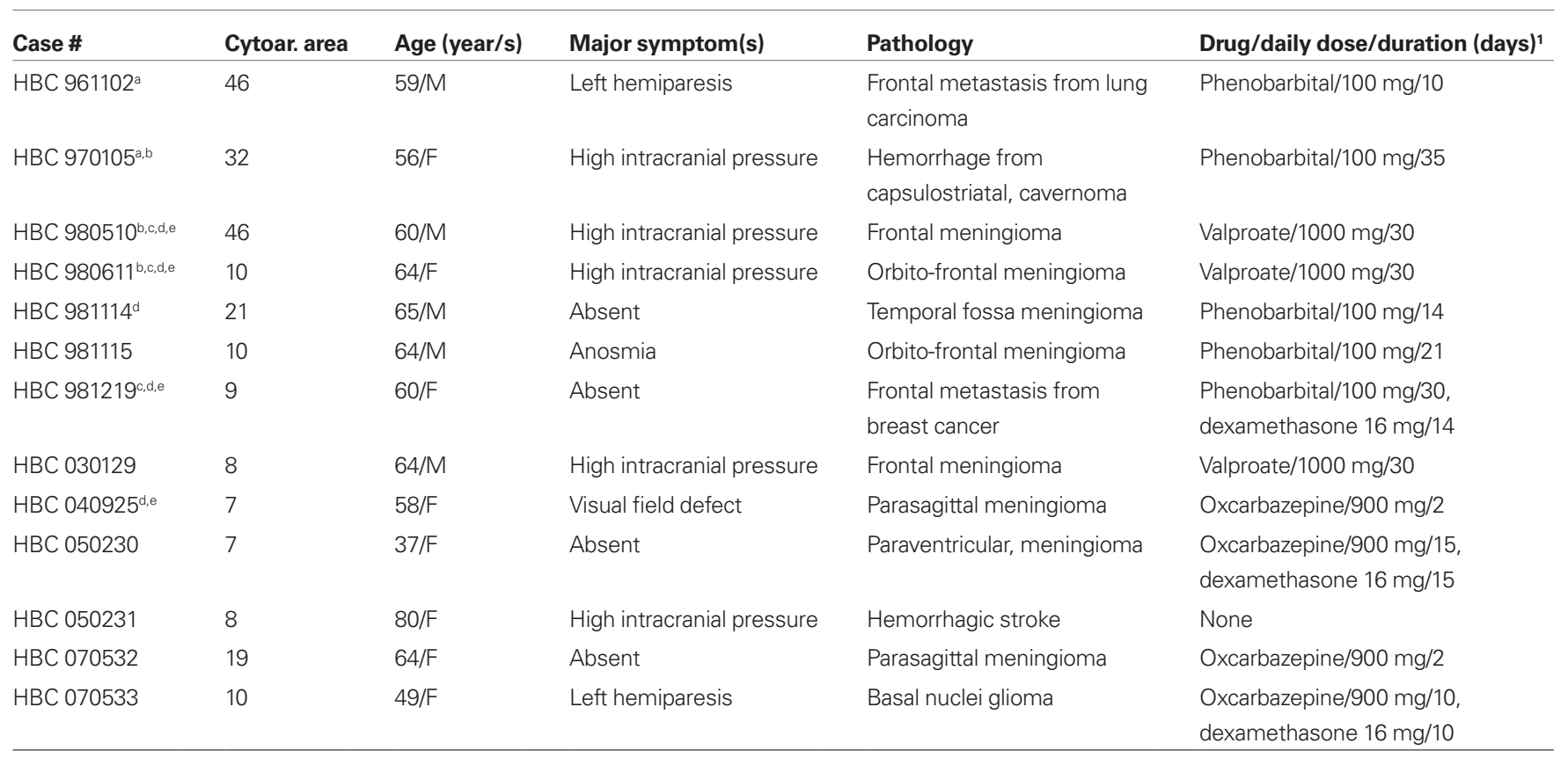

'Drugs used in perisurgical prophylactic therapy.

${ }^{a-e}$ Cases used in previous studies: ${ }^{a}$ Conti et al. (1998); bConti et al. (1999); ' Melone et al. (2004); dMelone et al. (2005a); ${ }^{\circ}$ Melone et al. (2006). 


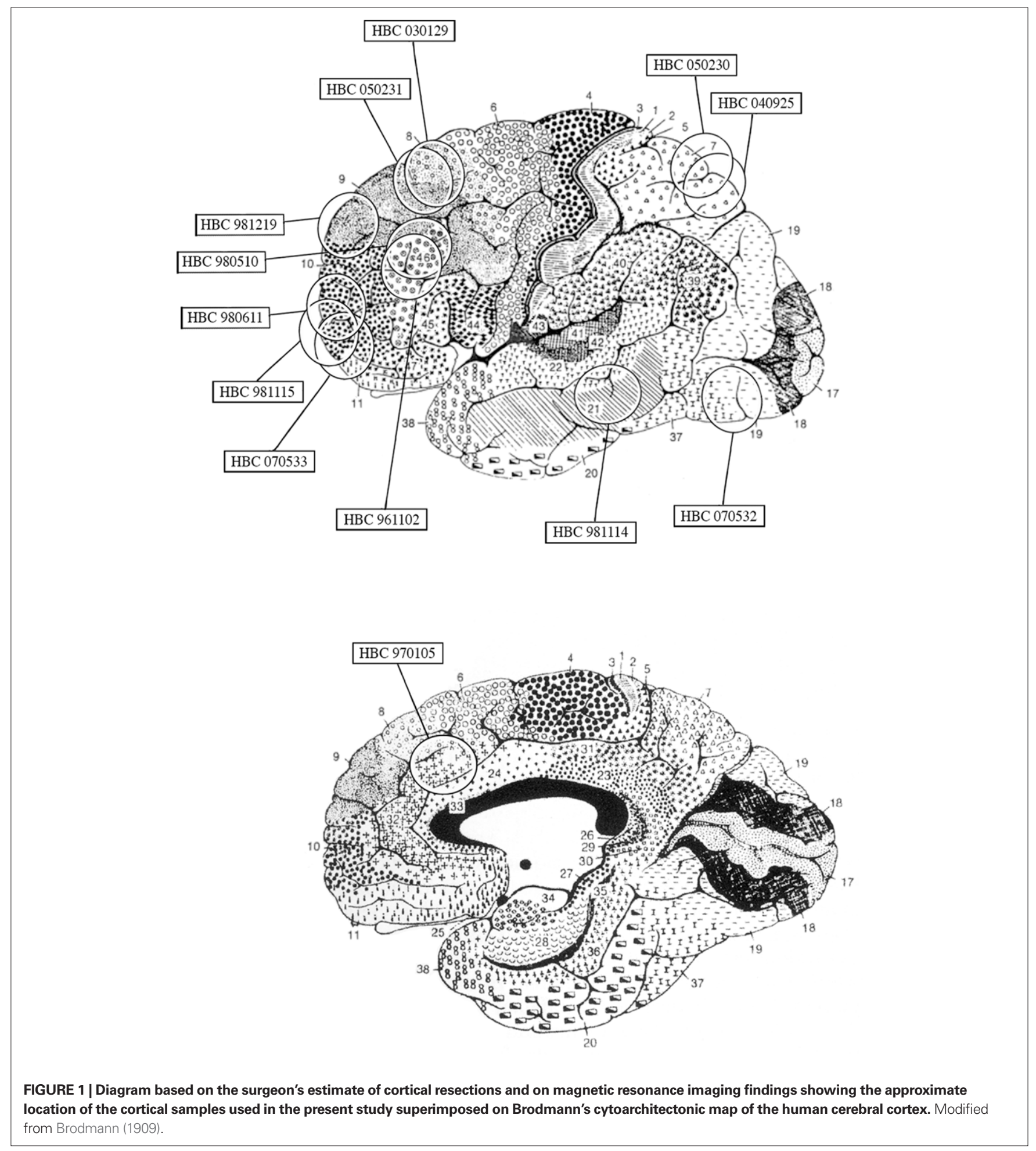

Monoclonal antibodies to glial fibrillary acidic protein (GFAP; Sigma, St Louis, MO, USA; GA5, G-3893) and polyclonal antibodies direct against the $\mathrm{C}$-terminus peptide GATHSTVQPPRPPPPVRDY of the rat vesicular glutamate transporter 1 (VGLUT1; Chemicon, Temecula, CA, USA; AB5905; characterized in Melone et al., 2005b) were also used.

\section{IMMUNOCYTOCHEMICAL PROCEDURE Immunoperoxidase}

Sections were treated with $\mathrm{H}_{2} \mathrm{O}_{2}(1 \%$ in $\mathrm{PB} ; 30 \mathrm{~min})$ to remove endogenous peroxidase activity, rinsed in $\mathrm{PB}$ and pre-incubated in $10 \%$ normal goat serum (NGS, $1 \mathrm{~h}$ ) with $0.2 \%$ Triton X-100 (the latter only for light microscopic studies). Sections were then incubated 
in a solution containing EAAT2a antibodies [0.3-0.5 $\mu \mathrm{g} / \mathrm{ml} ; 2 \mathrm{~h}$ at room temperature (RT) and overnight at $\left.4^{\circ} \mathrm{C}\right]$. The following day, sections were rinsed three times in $\mathrm{PB}$ and incubated first in $10 \%$ NGS $(15 \mathrm{~m})$ and then in a solution containing anti-rabbit biotinylated secondary antibodies (1:150; Vector, Burlingame, CA, USA, BA-1000; 1 h at RT). Sections were subsequently rinsed in $\mathrm{PBS}$, incubated in avidin-biotin peroxidase complex (ABC Elite PK6100, Vector), washed several times in $\mathrm{PB}$, and incubated in 3,3'-diaminobenzidine tetrahydrochloride (DAB; $0.05 \%$ in $0.05 \mathrm{M}$ Tris buffer, $\mathrm{pH} 7.6$ with $0.03 \% \mathrm{H}_{2} \mathrm{O}_{2}$ ). Method specificity was verified by substituting primary antibodies with PB or NGS. Sections were washed in PB, mounted on gelatin-coated slides, air-dried, coverslipped, and finally examined with a Leitz Orthoplan (Wetzlar, Germany) microscope.

After completion of ICC procedure, sections from cases HBC 980611,981115 , and 030129 were post-fixed in $1 \%$ osmium tetroxide in $\mathrm{PB}$ for $45 \mathrm{~m}$, and contrasted with $1 \%$ uranyl acetate in maleate buffer ( $\mathrm{pH} 6.0 ; 1 \mathrm{~h}$ ). After dehydration in ethanol and propylene oxide, sections were embedded in Epon/Spurr resin (Electron Microscopy Sciences, Hatfield, PA, USA), flattened between Aclar sheets (Electron Microscopy Sciences) and polymerized at $60^{\circ} \mathrm{C}$ for $(48 \mathrm{~h})$. Small blocks of tissue containing layers II/III (HBC 980611 and 030129) and white matter (HBC 981115 and 030129) were selected by light microscopic inspection, glued to blank epoxy and sectioned with an ultramicrotome (MTX; Research and Manufacturing Company Inc., Tucson, AZ, USA). The most superficial ultrathin sections $(\sim 60 \mathrm{~nm})$ were collected and mounted on 200 mesh copper grids, stained with uranyl acetate and Sato's lead and examined with a Zeiss EM 900 (Carl Zeiss NTS GmbH, Oberkochen, Germany).

\section{Immunofluorescence}

EAAT2a/VGLUT-1 double-labeling studies were performed on sections from cases HBC 050230, 05231, 070532, and 070533. Sections were washed in $\mathrm{PB}$, incubated in $10 \%$ NGS and $0.2 \%$ Triton X-100 in PB (1 h) and then in a solution containing a mixture of EAAT2a $(0.3 \mu \mathrm{g} / \mathrm{ml})$ and VGLUT1 $(1: 1000)$ primary antibodies ( $2 \mathrm{~h}$ at RT, overnight at $4^{\circ} \mathrm{C}$ ). Sections were washed and incubated first in 10\% NGS in PB (15 m) and then in a solution containing a mixture of affinity-purified fluorescein isothiocyanate (FITC, 1:250; Vector; FI1000/J0114)- or tetramethylrhodamine isothiocyanate (TRITC, 1:250; Molecular Probes, PoortGebouw, The Netherlands, T-2762/6691-1)-conjugated secondary antibodies (90 min). Sections were washed, mounted, air-dried and coverslipped using Vectashield mounting medium (H-1000; Vector) and finally examined with a Bio-Rad (Hemel Hempstead, UK) Microradiance confocal laser scanning microscope equipped with argon (488 nm) and helium/neon (543 nm) lasers. Control experiments with single-labeled sections and sections incubated with two primary antibodies and one secondary antibody or with one primary and two secondary antibodies revealed neither appreciable FITC/TRITC bleed-through nor antibody cross-reactivity.

\section{Immunogold}

Sections from cases HBC 980510, 981115, and 030129 were processed for an osmium-free embedding method (Phend et al., 1995). Briefly, dehydrated sections were immersed in propylene oxide, infiltrated with a mixture of Epon/Spurr resins, sandwiched between Aclar films, and polymerized at $60^{\circ} \mathrm{C}$ for $48 \mathrm{~h}$. After polymerization, chips including layers II/III were cut from the wafers, glued to blank resin blocks and sectioned with an ultramicrotome. Thin sections (60-80 nm) were cut and mounted on 300 mesh nickel grids and processed for immunogold labeling as described (Phend et al., 1992, 1995). Briefly, after treatment with $4 \% p$-phenylenediamine in Tris-buffered saline [0.1 M Tris, $\mathrm{pH} 7.6$, with $0.005 \%$ Tergitol N P-10 (TBST) ], grids were washed in TBST ( $\mathrm{pH} 7.6$ ), transferred for $15 \mathrm{~min}$ in $1 \%$ NGS in TBST ( $\mathrm{pH} 7.6$ ) and then incubated overnight in a solution of TBST ( $\mathrm{pH}$ 7.6) containing anti-EAAT2a primary antibodies $(6 \mu \mathrm{g} / \mathrm{ml})$. Grids were subsequently washed in TBST ( $\mathrm{pH} 8.2$ ), transferred for $10 \mathrm{~min}$ in $1 \%$ NGS in TBST ( $\mathrm{pH} 8.2$ ), incubated for $2 \mathrm{~h}$ in TBST ( $\mathrm{pH} 8.2$ ) containing IgG anti-rabbit secondary antibodies conjugated to $12 \mathrm{~nm}$ gold particles (1:20; 111-205-144, Jackson ImmunoResearch, West Grove, PA, USA) secondary antibodies, washed in distilled water, and then stained with uranyl acetate and Sato's lead. Ultrathin labeled sections were examined with a Philips EM 208 electron microscope coupled to a MegaView-II high resolution CCD camera (Soft Imaging System; Munster, Germany). Gold particles were not detected when primary antiserum was omitted; when normal serum was substituted for immune serum sparse and scattered gold particles were observed, but they did not show any relationship to astrocytic or axon terminal profiles.

The optimal concentration of anti-EAAT2a primary antibodies was sought by testing several dilutions; the concentration yielding the lowest level of background labeling and still immunopositive elements was used to perform the final studies.

\section{WESTERN BLOTTING}

Total amount of protein was determined according to the Bradford method (Bradford, 1976) using the Bio-Rad Protein Assay (Bio-Rad Laboratories, GmbH, München, Germany) and a Beckman DU 530 spectrophotometer (Beckman Coulter, Fullerton, CA, USA; 3-4 measurements). Aliquots of homogenates (2.5-15 $\mu \mathrm{g}$ of total protein) were subjected to SDS-PAGE; separated proteins were electroblotted onto nitrocellulose filters which were probed with antibodies to EAAT2a $(0.02 \mu \mathrm{g} / \mathrm{ml})$. After exposure to peroxidase conjugated secondary antibodies (Vector, Burlingame, CA, USA), bands were visualized by Bio-Rad Chemidoc and Quantity One software using the SuperSignal West Pico (Rockford, IL, USA) chemiluminescent substrate (Bragina et al., 2006 for details).

\section{DATA COLLECTION AND ANALYSIS}

Cytoarchitectonic areas and boundaries were identified on Nisslstained sections adjacents to the those used for immunocytochemical studies, according to Brodmann (1909), von Economo (1928), Clarke and Miklossy (1990), Ong and Garey (1990), Rajkowska and Goldman-Rakic (1995), Vogt et al. (1995); Semendeferi et al. (2001), Scheperjans et al. (2008).

\section{Confocal microscopy}

Fields from layers II/III (2 sections/case; 4 cases) were randomly selected and $Z$-axis image stacks were acquired ( $\mathrm{z}$-step size $0.6 \mu \mathrm{m}$ ) for each fluorescent as $1024 \times 1024$ pixel images with a planapo $\times 63$ objective (numerical aperture 1.4 ) and pinhole 1.0 Airy unit. 
To improve signal/noise ratio, eight frames of each images were averaged; microscopic fields were scanned with a pixel size of $80 \mathrm{~nm}$. Quantitative analysis was performed in randomly selected $10 \mu \mathrm{m} \times 10 \mu \mathrm{m}$ fields from each $1024 \times 1024$ pixel image; to achieve optimal detection and resolution only images collected at the very surface of stained sections were used to study EAAT2a and VGLUT1 punctate immunostaining (Melone et al., 2005b, 2009). Image processing was performed on Photoshop CS2 (Adobe Systems, San Jose, CA, USA) and threshold levels were set as described (Melone et al., 2005b, 2009). To identify any overlap between EAAT2apositive (+) and VGLUT1+ puncta, the channel corresponding to EAAT2a was examined first and each positive puncta identified. The second channel (corresponding to VGLUT1) was then viewed and the presence or absence of overlap was noted for each field.

\section{Pre-embedding electron microscopy}

EAAT2a immunopositive profiles were studied from ultrathin sections at the surface of the embedded blocks. Quantitative data on EAAT2a immunopositive profiles derived from the analysis of $3120 \mu \mathrm{m}^{2}$ of cortical neuropil (2-4 grids/case; 2 cases) and of $1500 \mu \mathrm{m}^{2}$ of white matter ( 3 grids/case; 2 cases). Fields with EAAT2a+ profiles were randomly selected and captured at 12,000 or 20,000×. Microscopic fields used to evaluate EAAT2a localization at synapses were selected and captured at original magnifications of $\times 30,000$ or 50,000. Micrographs were digitized using a scanner connected to a Macintosh platform. Cells and cellular elements were identified according to Peters et al. (1991).

\section{Post-embedding immunogold electron microscopy}

Ultrathin sections ( 3 grids/ 3 cases) were examined at 50,000-85,000× and fields that included at least 1 immunolabeled perisynaptic astrocytic profile and/or axon terminal associated with an asymmetric synapse exhibiting a clear AZ-PSD complex were selected (Peters et al., 1991; Tyler and Pozzo-Miller, 2001). To determine the relative density of EAAT2a in subcellular compartments, astrocytic profiles, axon terminals, and pyramidal cell nuclei were identified; gold particles within labeled structures were counted and areas were calculated using ImageJ version 1.29 software (NIH, Bethesda, MD, USA). Background was calculated by estimating labeling density over pyramidal cell nuclei (Racz and Weinberg, 2004; Melone et al., 2009). Particle densities were counted and compared with background labeling. Gold particles were considered associated with plasma membrane if they were within $15 \mathrm{~nm}$ of the extracellular side of the membrane, and cytoplasmic if they were $>25 \mathrm{~nm}$ from the extracellular side of the membrane. Localization of a plasma membrane-associated gold particle with respect to the AZ margin was defined as described by Kharazia and Weinberg (1997) and Valtschanoff and Weinberg (2001). Briefly, the lateral position of a gold particle was defined as the distance along the plasma membrane from the AZ edge to the center of the particle (Valtschanoff and Weinberg, 2001; Racz and Weinberg, 2004); distance was measured using ImageJ software. The distance of gold particles coding for EAAT2a from AZ margin in both axon terminals and astrocytic processes was normalized to allow data pooling using the equation $X_{\mathrm{N}}=1-\left|x_{1}-x_{2}\right| / x_{1}+x_{2}$, where $x_{1}$ and $x_{2}$ correspond respectively to the distances from the closer and farther edges of the AZ, respectively (Racz and Weinberg, 2004).
Statistical analysis was performed using GraphPrism v.4.0 (GraphPad Software, San Diego, CA, USA); $\alpha=0.05$.

\section{RESULTS}

Examination of Nissl and GFAP-stained sections adjacent to those used for EAAT2a studies revealed that they were both devoid of any appreciable abnormalities and consistent with previous description of normal tissue (Hansen et al., 1987; Marco et al., 1996). EAAT2a-immunoreactivity (ir) in both gray and white matter was totally abolished when EAAT2a antibodies were substituted with NGS or PB (not shown) or blocked with EAAT2 $\mathrm{a}_{559-573}$ synthetic peptide (Figure 2A). Western blotting studies of cortical homogenates showed that EAAT2a antibodies recognized a single band of $\sim 70 \mathrm{kDa}$ (Figure 2B), consistent with the known molecular weight of EAAT2a.

\section{DISTRIBUTION OF EAAT2a-ir IN HUMAN CEREBRAL CORTEX}

Light microscopic examination revealed that EAAT2a-ir in prefrontal, parietal, temporal, occipital, and cingulofrontal cortical areas (areas 46, 8, 9, 10,7, 19,21, and 32) was present in all cortical layers, without any preferential distribution (Figure 3 ); in all cortices, small irregular areas of reduced immunostaining were evident (Figure 3). In gray matter, EAAT2a-ir consisted of small punctate structures scattered in the neuropil (Figures 4A-E); small EAAT2apositive $(+)$ cells with intensely stained processes were occasionally noticed in layers I and VI, (Figure 4D); EAAT2a+ profiles were frequently present along blood vessels (Figure 4E). In the white matter underlying the cortex, EAAT2a+ cells, as well as perivascular EAAT2a+ profiles (Figures $4 \mathbf{F}-\mathbf{H}$ ), were numerous.

\section{CELLULAR LOCALIZATION OF EAAT2a-ir IN HUMAN CEREBRAL CORTEX}

Electron microscopic studies of immunoperoxidase pre-embedded material from layers II/III of areas 8 and 10 showed that electrondense reaction product was frequently observed in the cytoplasm of astrocytes (Figure 5A) and, rarely, in that of neurons (Figure 5B).

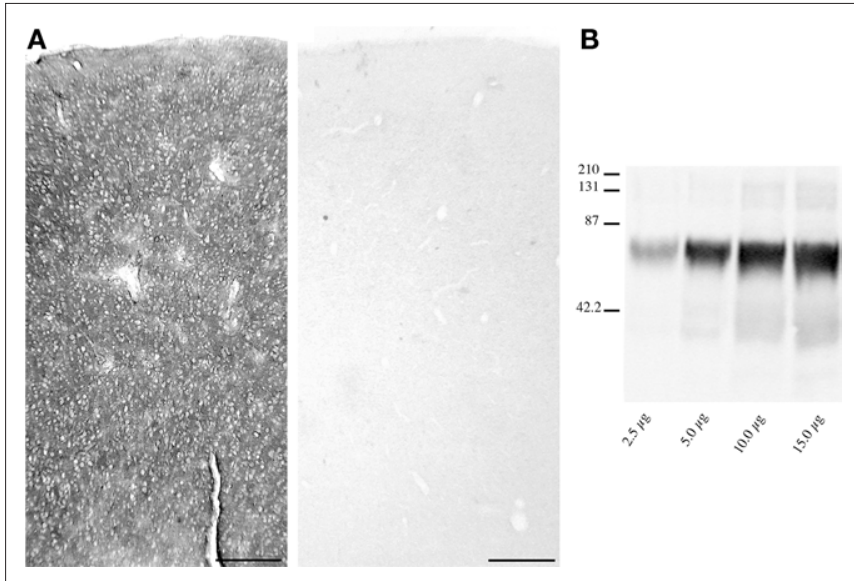

FIGURE 2 | Method specificity. (A) EAAT2a-ir in human cortex (area 46, HBC 961102; left) is completely abolished (right) by preincubation of EAAT2a antibodies with $10^{-3} \mathrm{M}$ of EAAT2 $\mathrm{a}_{559-573}$ synthetic peptide. (B) Western blottings of cortical synaptic membranes (area 7, HBC 040925) shows that EAAT2a antibodies recognize a band of $\sim 70 \mathrm{kDa}$ among a wide range of total protein loaded (from 2.5 to $15.0 \mu \mathrm{g} /$ lane). Scale bar: $200 \mu \mathrm{m}$ for (A). 

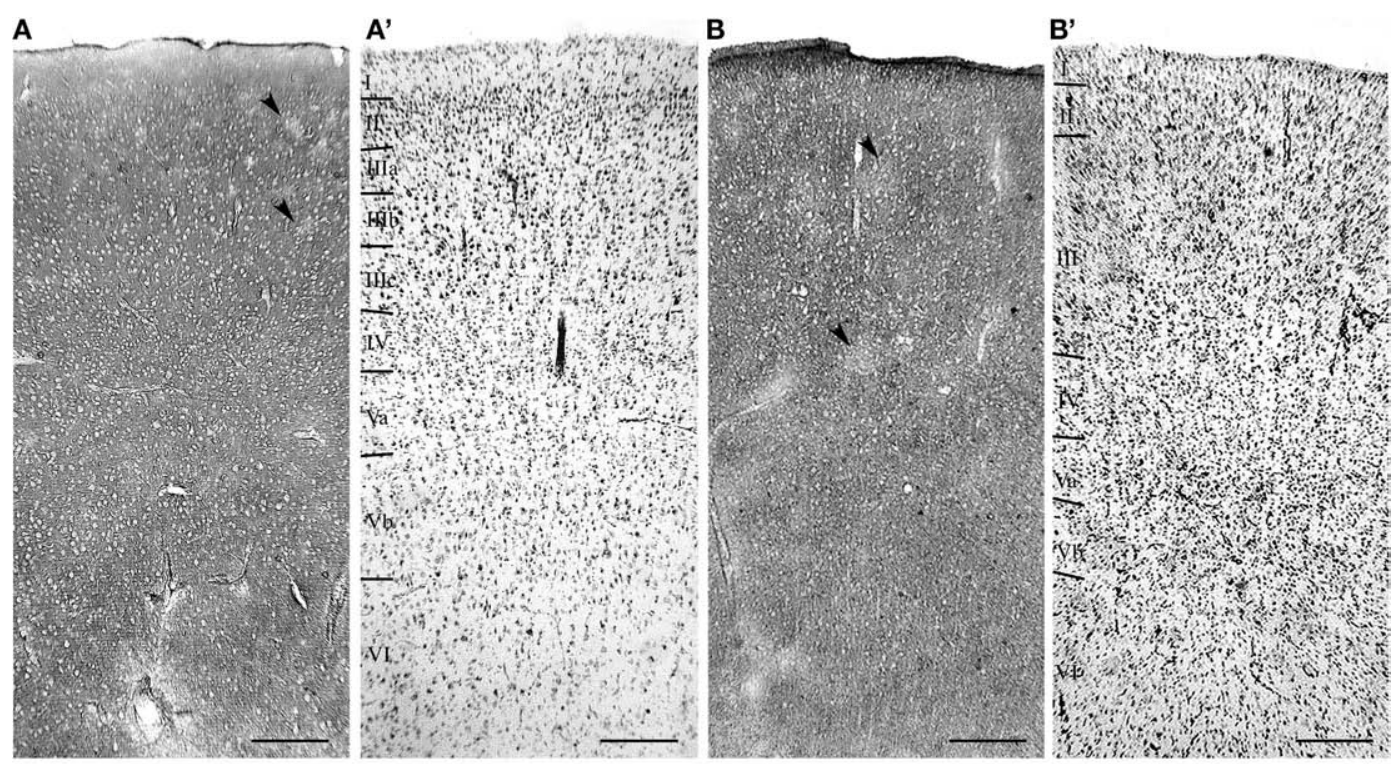

C

$C^{\prime}$

D

D'
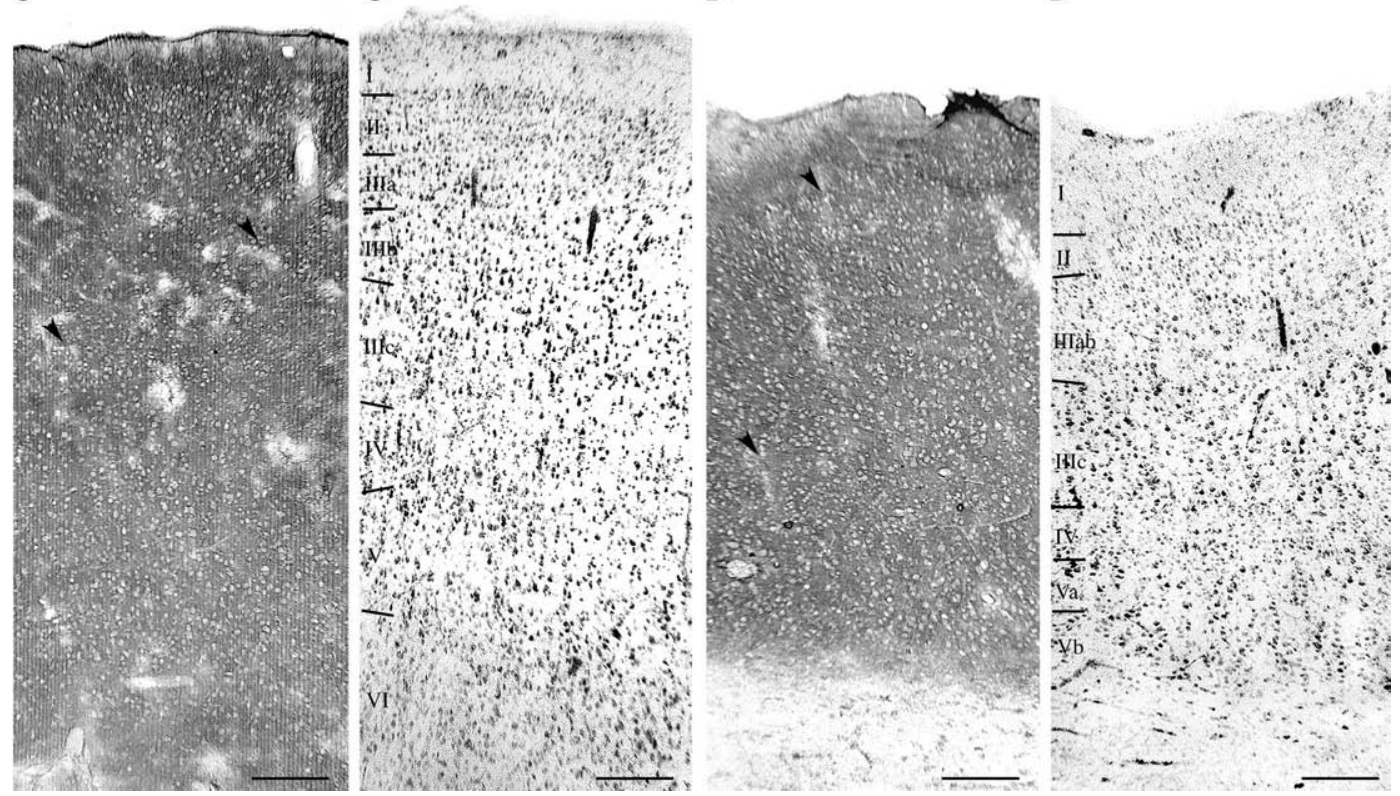

FIGURE 3 | Distribution of EAAT2a-ir in human cerebral cortex. (A-D) EAAT2a-ir in prefrontal [(A) area 46; HBC 980510], parietal [(B) area 7; HBC 050230],

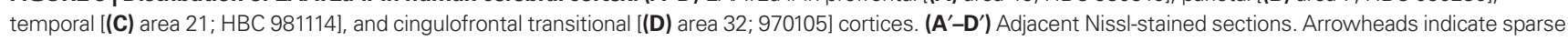
and irregular patchy areas of limited EAAT2a-ir. Roman numerals indicate cortical layers. WM, white matter. Scale bar: 250 um for (A-D,A'-D').

EAAT2a-ir was never observed in the cytoplasm of microglia cells and oligodendrocytes. In the neuropil, EAAT2a-ir was in astrocytic processes, axon terminals, and dendrites (Figures $5 \mathrm{C}-\mathrm{E}$ ): a quantitative analysis showed that out of 449 EAAT2a+ elements (from 126 microscopic fields) $77.1 \pm 2.5 \%$ were astrocytic processes, $14.2 \pm 2.1 \%$ were axon terminals; $2.8 \pm 1.1 \%$ were dendrites and $5.4 \pm 1.2 \%$ were not identifiable (Figure 5F). In the white matter underlying areas 8 and 10, EAAT2a-ir was in the cytoplasm and processes of numerous fibrous astrocytes (Figures 5G,H), and in myelinated axons (Figure 5I); out of 245 positive elements (from 63 microscopic fields), $81.8 \pm 3.2 \%$ were astrocytic processes,
$17.1 \pm 3.4 \%$ were myelinated axons and $2.0 \pm 0.8 \%$ were not identified (Figure 5J). EAAT2a-ir was never observed in microglial cells and oligodendrocytes.

\section{SYNAPTIC LOCALIZATION OF EAAT2a-ir IN HUMAN CEREBRAL CORTEX Confocal and pre-embedding electron microscopic studies}

Next, we investigated whether EAAT2a is expressed in the vicinity or at some distance from asymmetric synapses by double-labeling studies of EAAT2a and VGLUT1 ir, which are typically seen as puncta dispersed in the neuropil (Minelli et al., 2001; AlonsoNanclares et al., 2004; Melone et al., 2005b, 2009). High resolution 


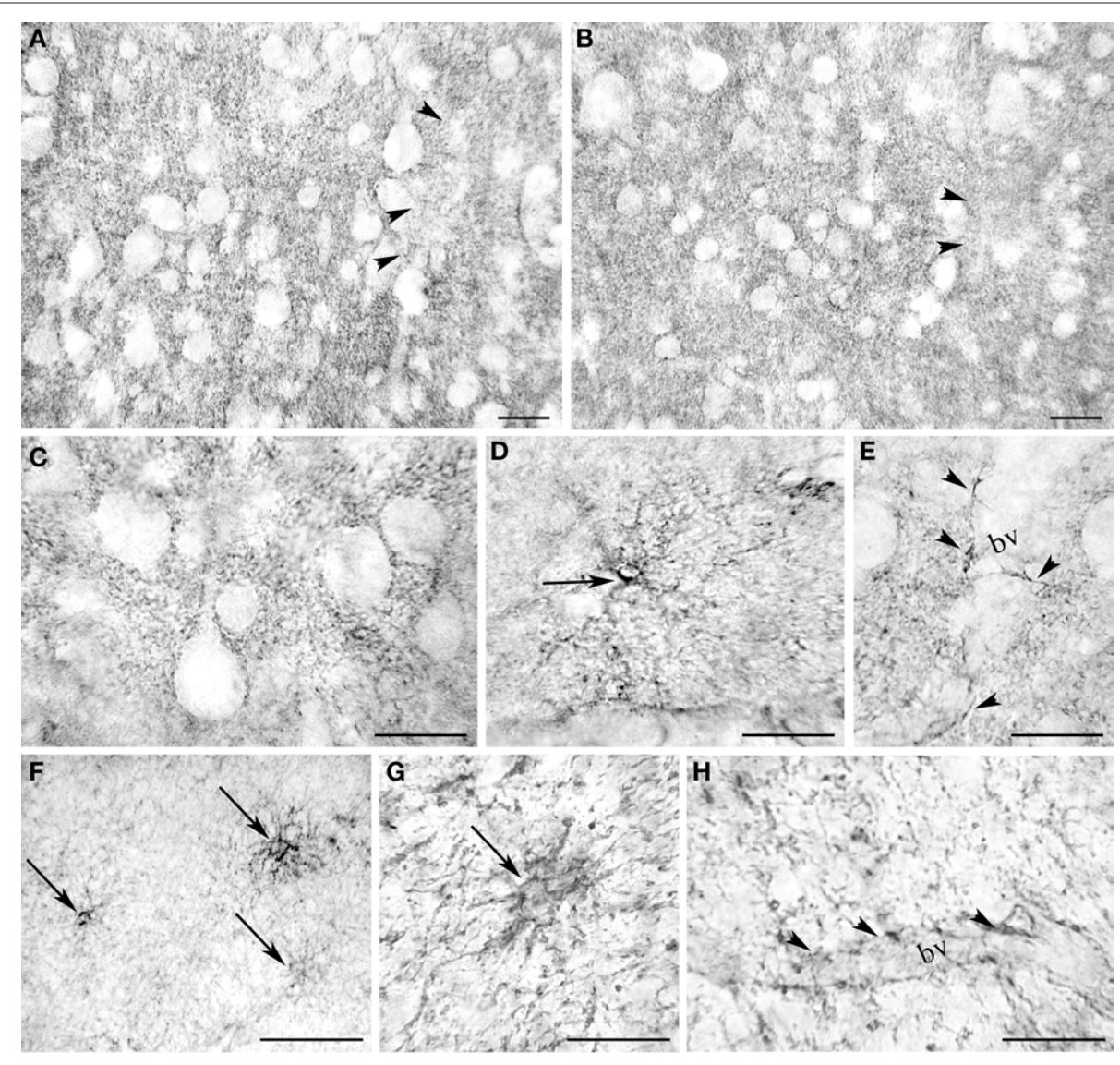

FIGURE 4 | Light microscopic analysis of EAAT2a-ir in human cerebral cortex. (A-E) In cortical gray matter (area 46; HBC 961102) EAAT2 ir is characterized by widespread EAAT2a + puncta dispersed in the neuropil [(A) layers II/III; (B) layer IV] or outlining unstained cells bodies [(C) layer II/III], rare intensely stained cells in layer I (D), and perivascular profiles (E) (layers II/III). (F-H) In the white matter underlying the cortex (area 32; HBC 970105) EAAT2a-ir is in cells resembling astrocytes (F,G) and in perivascular profiles (H). bv, blood vessel. Arrowheads in $(\mathbf{A}, \mathbf{B})$ indicate patchy areas of limited EAAT2a-ir; arrows in $\mathbf{( D , F , G ) ~ p o i n t ~ t o ~}$ intensely stained astrocyte-like cells; and arrowheads in $\mathbf{( E , H )}$ indicate EAAT2 ir perivascular profiles. Scale bars: $20 \mu \mathrm{m}$ for (A-E,G-H); $50 \mu \mathrm{m}$ for (F). confocal microscopy of EAAT2a (TRITC)/VGLUT1 (FITC) double labeled fields from layers II/III of areas 7, 8, 10, and 19 showed that red and green puncta were morphologically different and separated; however, in all merged images many puncta were at least partially yellow (Figures $6 \mathbf{A}-\mathbf{A}^{\prime \prime}$ ), indicating a spatial overlap of the two signals. All signal overlap was taken to indicate EAAT2a expression in the vicinity of the glutamatergic synapse (Melone et al., 2009); we estimated that $40.3 \pm 1.5 \%$ of EAAT2a+ puncta ( $n=2285 ; 20$ microscopic fields) overlapped with VGLUT1+ puncta. Electron microscopy confirmed that EAAT2+ profiles were both in intimate association with asymmetric synapses and far from the synapses (Figure 6B). To better define the organization of synapses expressing EAAT2a, we performed a pre-embedding electron microscopy analysis of asymmetric synapses $(n=130$; layers II/III; areas 8 and 10). These studies showed that $67.9 \pm 4.0 \%$ of EAAT2a expressed at asymmetric synapses was in astrocytic processes, $17.9 \pm 3.3 \%$ in axon terminals, while $13.4 \pm 2.9 \%$ was both in astrocytic processes and in axons (Figures 6C-F). Overall, these data indicated that about half of cortical EAAT2a is in the vicinity of asymmetric synapses and that about $70 \%$ of the latter is in astrocytic processes.

\section{Post-embedding immunogold studies}

In samples from layers II/III of areas 8,10 , and 46 processed for immunogold post-embedding electron microscopy, gold particles were observed in both distal astrocytic processes (Figure 7A) and axon terminals (Figure 7B). In astrocytic processes contacting asymmetric synapses $(n=97)$ and in axon terminals $(n=46)$, gold particle density was $25.11 \pm 3.6$ and $2.8 \pm 0.4$ particles $/ \mu \mathrm{m}^{2}$, respectively, and was significantly higher (two-tailed $t$-test: $P<0.005$ and $P<0.0001)$ than background, estimated by calculating gold particle density over pyramidal cell nuclei $(n=13 ; 0.4 \pm 0.04$ particles $\left./ \mu \mathrm{m}^{2}\right)$. Next, we ascertained whether gold particles coding for EAAT2a were preferentially localized near the plasma membrane of astrocytic processes and axon terminals by comparing the number of gold particles associated to the membrane (within $15 \mathrm{~nm}$ of the extracellular side of the membrane) and of those not associated to it ( $>25 \mathrm{~nm}$ from the extracellular side of the membrane). In both astrocytic processes and axon terminals, the density of membrane-associated gold particles $(59.3 \pm 4.6$ and $41.9 \pm 4.4$ particles $/ \mu \mathrm{m}^{2}$, respectively) was much higher than that of gold particles not associated to membrane $(28.1 \pm 5.2$ and $3.4 \pm 0.2$ particles $/ \mu \mathrm{m}^{2}$; two-tailed $t$-test: $\left.P<0.0001\right)$. The density 

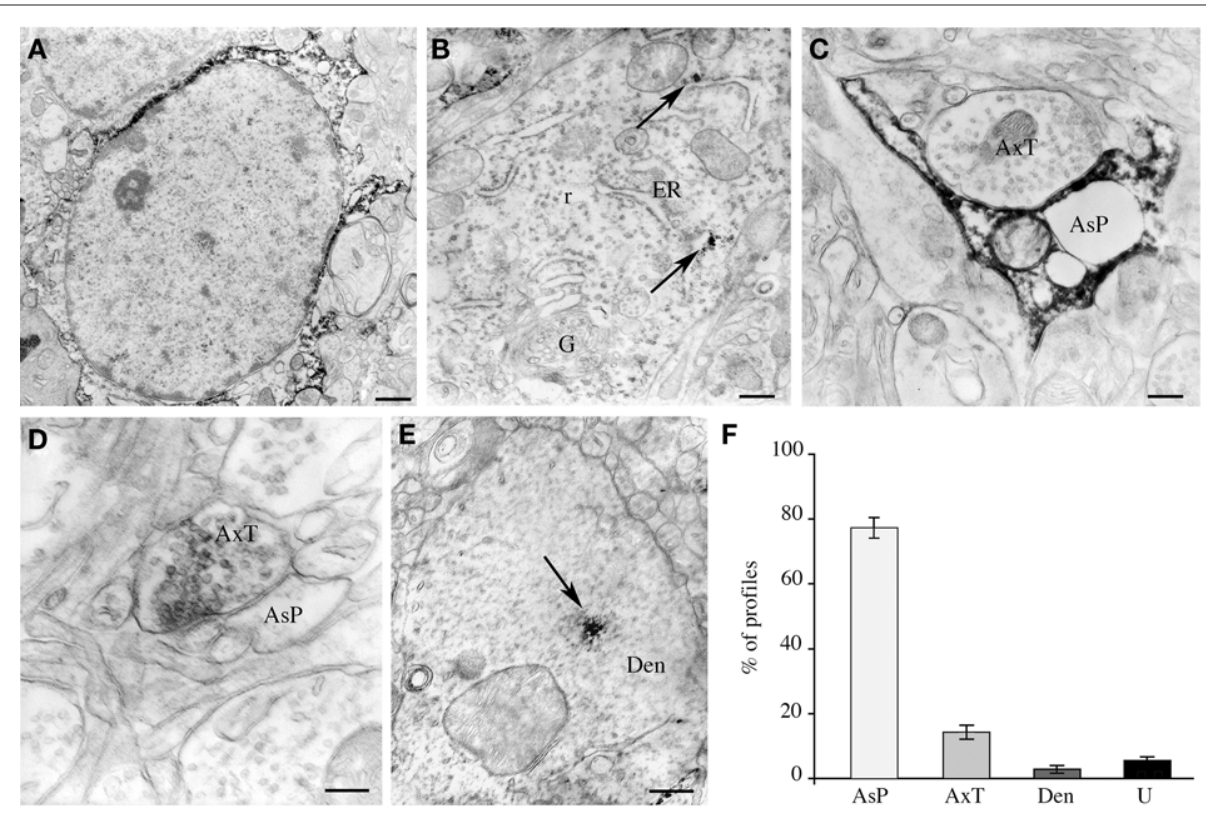

F 100
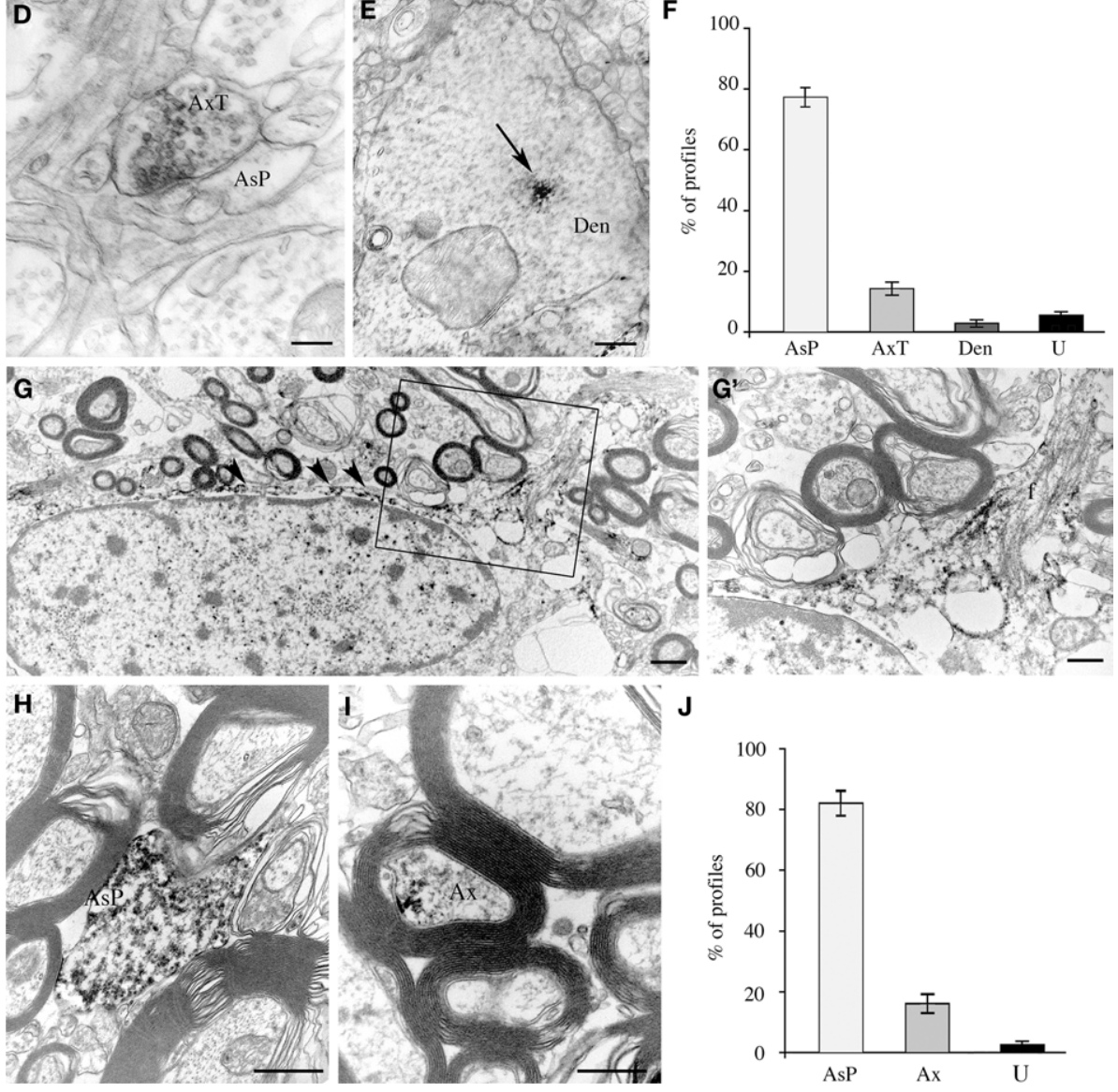

FIGURE 5 | Cellular localization of EAAT2a-ir in human cerebral cortex studied by pre-embedding electron microscopy. (A-E) In gray matter, EAAT2 ir is localized to astrocytes (A) and rarely in neurons (B), where it is closely associate to endoplasmic reticulum (arrows). In the neuropil, EAAT2a is observed in astrocytic processes (C), axon terminals (D), and dendrites (E) Area 10; case HBC 980611. (F) Quantification of EAAT2a+ profiles in gray matter. (G-I) In white matter, EAAT2 ir is in fibrous astrocytes [arrowheads in
(G)] and along their fibrous processes [(G'); enlargement from the framed region in (G)], in astrocytic processes $\mathbf{( H )}$ and in myelinated axons (I). Area 10; case HBC 981115. (J) Quantification of EAAT2a+ profiles in white matter. Ax, myelinated axon; AxT, axon terminal; AsP, astrocytic process; Den, dendrite; ER, endoplasmic reticulum; f, astrocyte fibrous filament; G, Golgi apparatus; r, ribosomes; $U$, unidentified profiles. Scale bars: $0.8 \mu \mathrm{m}$ for $(\mathbf{A}, \mathbf{G}) ; 0.1 \mu \mathrm{m}$ for (B); 0.25 for (C); $0.15 \mu \mathrm{m}$ for (C,D); $0.3 \mu \mathrm{m}$ for $\left(\mathbf{G}^{\prime}, \mathbf{I}\right)$; and 0.4 for $\mu \mathrm{m}$ (J). of membrane-associated gold particles was significantly higher in astrocytic processes than in axon terminal (two-tailed $t$-test: $P<0.005)$. Finally, we measured the distance on the plasma membrane between gold particles coding for EAAT2a and AZ edges. In astrocytic processes contacting asymmetric synapses $(n=99)$, gold particles $(n=108)$ were found over a wide distance range (mean distance: $360.9 \pm 23.4 \mathrm{~nm}$ ) and were concentrated at $60-220 \mathrm{~nm}$ from the AZ edge, with a peak at 120-140 nm (Figures 7C-E). In axon terminals $(n=46)$, particles were also distributed over a wide distance range (mean distance: $277.1 \pm 36.9 \mathrm{~nm} ; n=51$ ) and were concentrated at $40-160 \mathrm{~nm}$ from AZ edge with a peak at $60 \mathrm{~nm}$ (Figures 7F-H). The position of the EAAT2a coding particles was then normalized such that 0 corresponded to the AZ edge and 1.0 to the point along the perimeter equidistant from both $A Z$ edges in the case of axon terminals or from the AZ edge ipsilateral to the astrocytic process displaying gold particles. Normalized data 

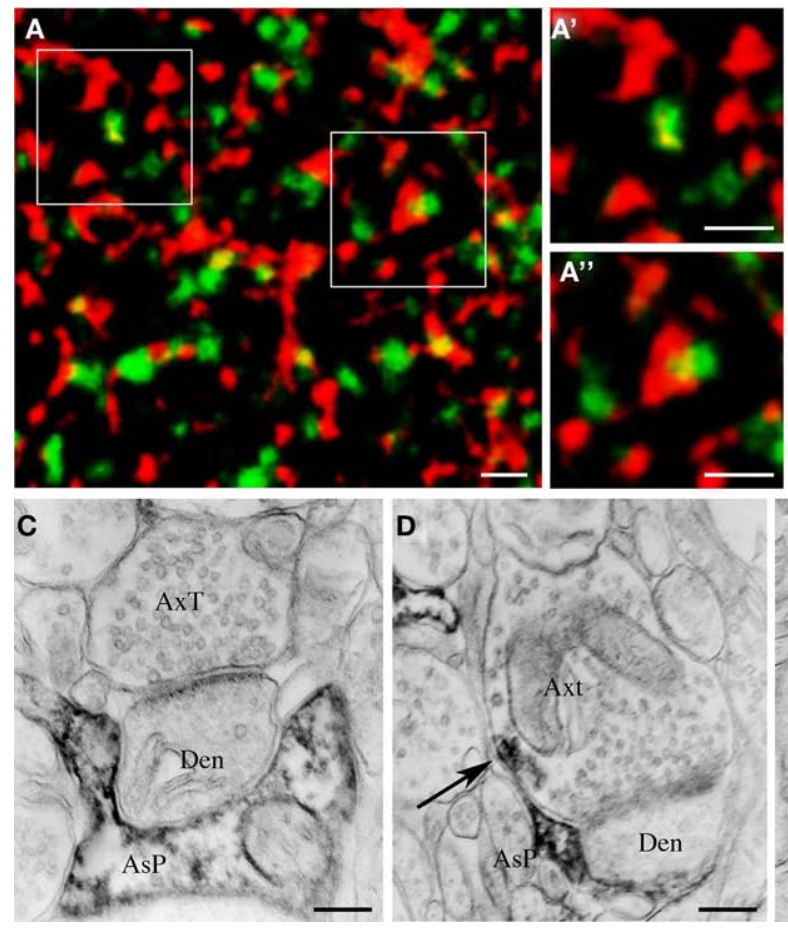

FIGURE 6 | Synaptic localization of EAAT2a-ir in human cerebral cortex: confocal and pre-embedding electron microscopic studies. (A) Simultaneous visualization of EAAT2a (red) and VGLUT1 (green) shows variable degree of overlap between the two signals; $\left(\mathbf{A}^{\prime}, \mathbf{A}^{\prime \prime}\right)$ are enlargements of framed regions in (A). Area 11; HBC 070533. (B) Pre-embedding electron microscopy confirms the presence of EAAT2 ir in intimate association with (arrowheads) and far from (arrow) asymmetric synapses. Area 8, HBC 030129. (C-E) Examples of
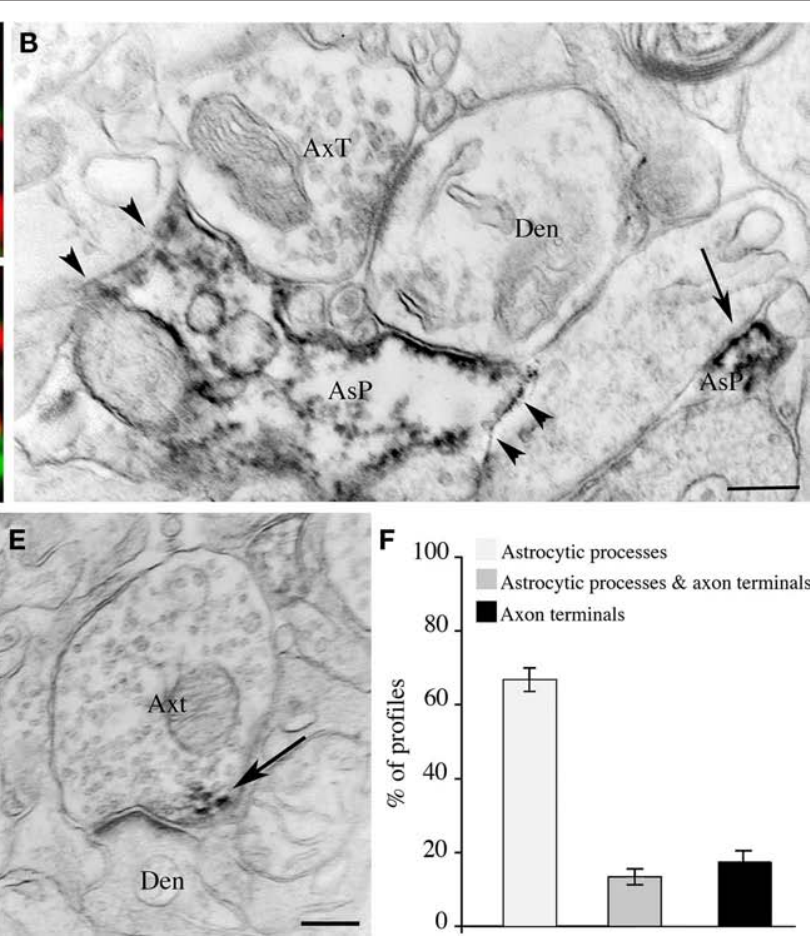

showed that membrane-associated EAAT2a of axon terminals or astrocytic processes was at mean tangential distance from AZ edge of $0.31 \pm 0.03$ and $0.35 \pm 0.02$, respectively. Two-tailed $t$-test showed that the two populations were comparable $(P>0.05)$. These studies showed that the density of membrane-associated EAAT2a molecules is higher in astrocytic processes than in axon terminals and indicated that in both axon terminals and astrocytic processes contacting asymmetric synapses most EAAT2 is concentrated in a membrane region extending for about $300 \mathrm{~nm}$ from the AZ edge.

\section{DISCUSSION}

These studies provide the first detailed description of the cellular and synaptic localization of EAAT2a in human cerebral cortex. They show that: (1) EAAT2a is expressed in all layers, where it is localized to astrocytes and neurons. Astrocytic processes and axon terminals are $\sim 75$ and $\sim 15 \%$ of all EAAT2a-positive elements, respectively; (2) about half of cortical EAAT2 is in the vicinity of cortical synapses and $70 \%$ of it is in astrocytic processes; (3) in post-embedding electron microscopic studies the density of gold particles coding for EAAT2a in astrocytic processes is about 10 times higher than in axon terminals; and (4) in both axon terminals and astrocytic processes most EAAT2a is concentrated in a membrane region extending for $\sim 300 \mathrm{~nm}$ from the active zone edge.
EAAT2a localization to (1) astrocytic processes in intimate association with asymmetric synapses whose axon terminal is not EAAT2a-ir (C); (2) astrocytic processes in close association with EAAT2a+ axon terminals forming asymmetric synapses [arrow in (F)]; and (3) axon terminals making asymmetric synapses [arrow in (E)]. Area 8, HBC 030129. (F) Proportion of the different organizational models. Den, dendrite; AsP astrocytic process; $\mathrm{AxT}$, axon terminals. Scale bars: $1 \mu \mathrm{m}$ for $\left(\mathbf{A}-\mathbf{A}^{\prime \prime}\right) ; 0.25 \mu \mathrm{m}$ for (B-E).

\section{DISTRIBUTION OF EAAT2 IN CEREBRAL CORTEX: COMPARISON WITH PREVIOUS STUDIES AND METHODOLOGICAL CONSIDERATIONS}

We exposed bioptic samples of human neocortex to specific antibodies directed against a synthetic peptide corresponding to the common rodent and human EAAT2a C-terminal sequence 559-573 (Pines et al., 1992; Arriza et al., 1994). Studies in EAAT2 knockout mice showed that EAAT2a-ir revealed by these antibodies is genuine (Chen et al., 2004; Omrani et al., 2009). In addition, we performed conventional controls employed in human studies, i.e., western blotting of synaptic membranes and pre-absorption with EAAT2a synthetic peptide (Saper and Sawchenko, 2003; Fritschy, 2008). These data indicated that EAAT2a-ir detected in our experimental conditions is specific.

The distribution of EAAT2 ir has been described in previous light microscopic studies, with different results. In some reports, EAAT2 ir is strong in somata and proximal processes of glial-like cells irregularly scattered in cortical parenchyma, without a diffuse neuropilar staining (“irregular pattern"; Milton et al., 1997; Fray et al., 1998; Proper et al., 2002; Furuta et al., 2005; Matute et al., 2005; Williams et al., 2005), whereas in others EAAT2 is described in punctate structures scattered in the neuropil ("regular pattern"; Rothstein et al., 1995; Bar-Peled et al., 1997; Ikematsu et al., 2001; Bjornsen et al., 2007). Our results agree with those reporting a "regular" pattern of EAAT2 ir. Differences in immunocytochemical detection in human material may be accounted for by primary antibodies 

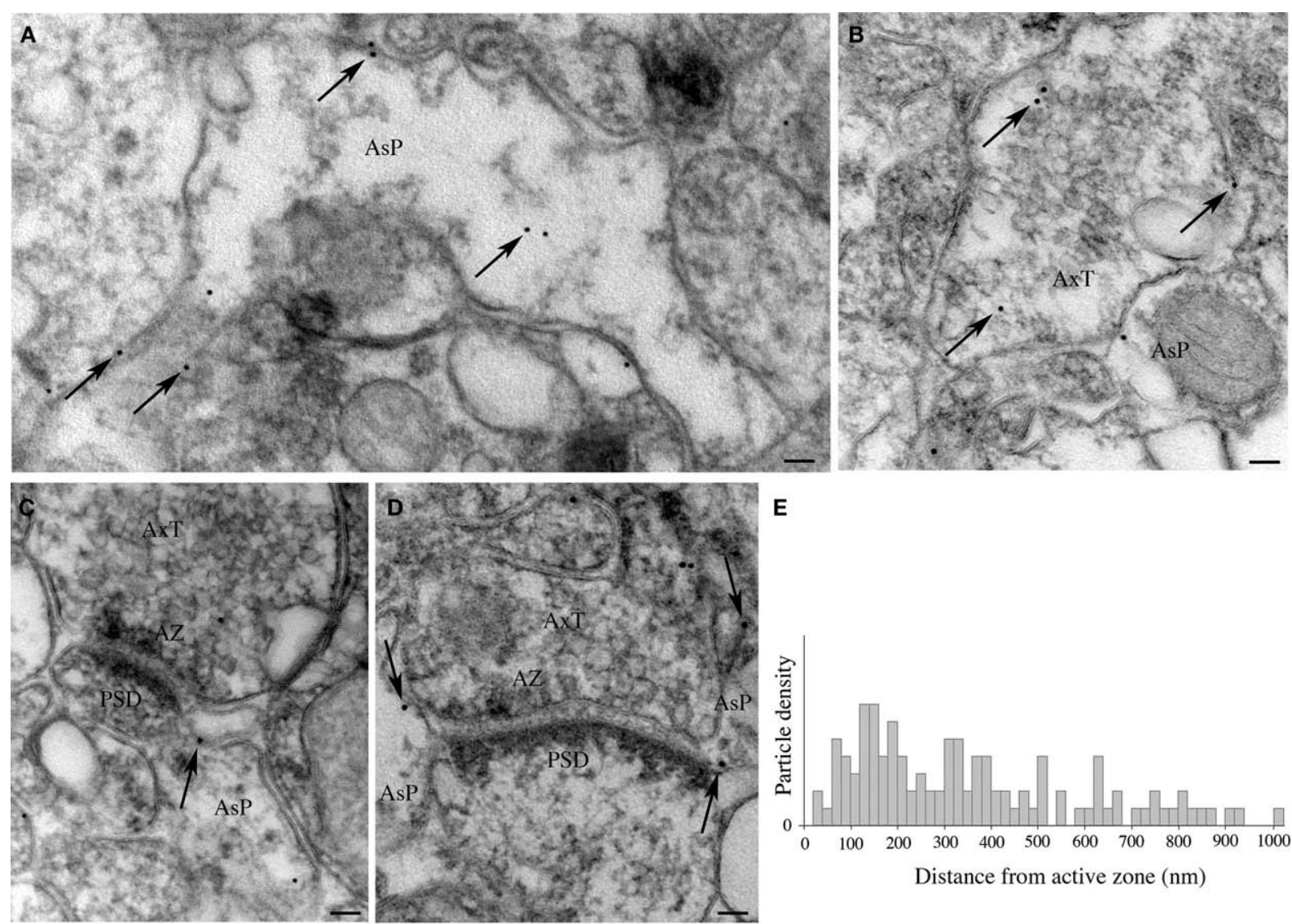

E
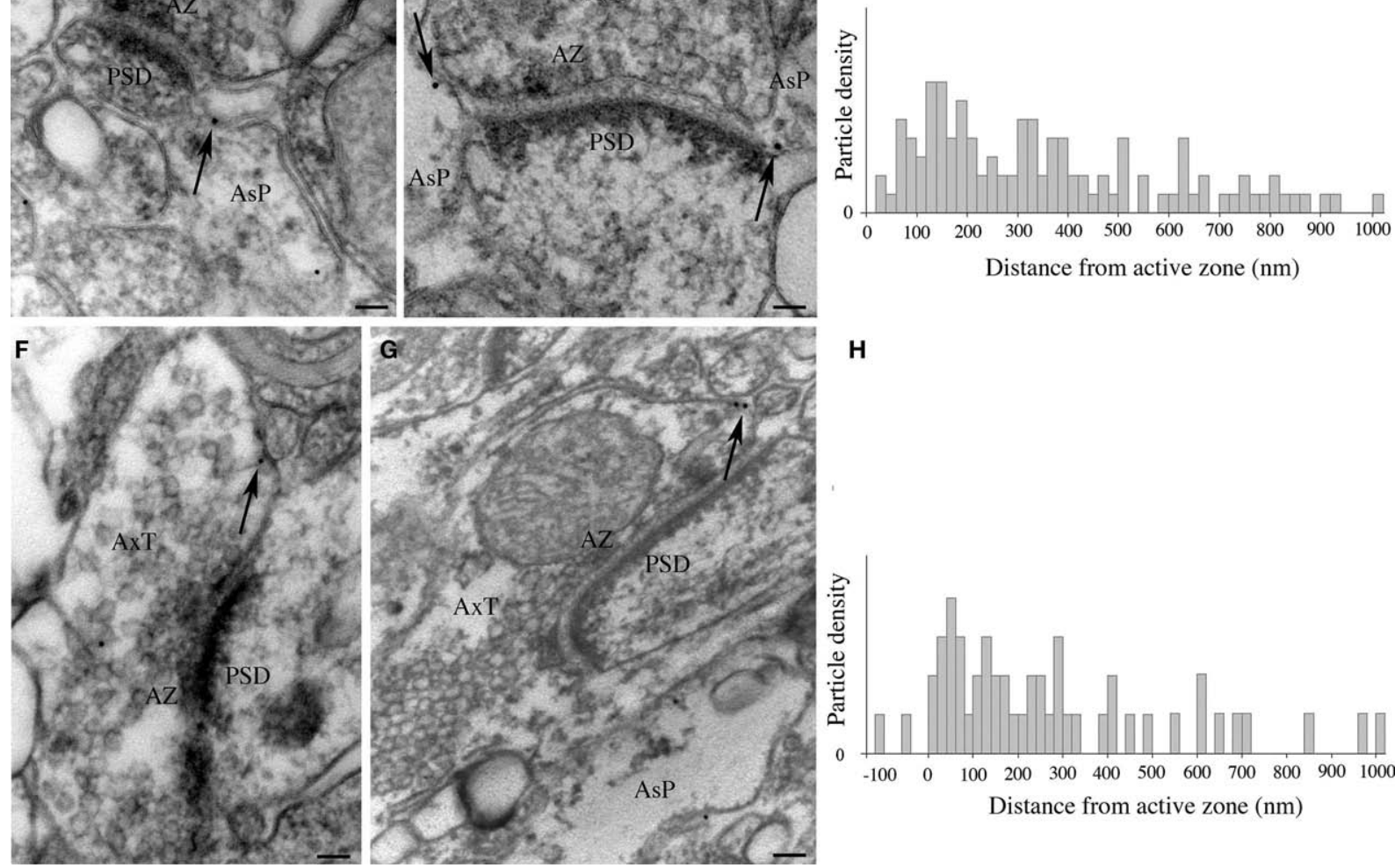

Distance from active zone $(\mathrm{nm})$

\section{H}

FIGURE 7 | Synaptic localization of EAAT2a-ir in human cerebral cortex: post-embedding immunogold studies. $(A, B)$ Visualization of gold particles coding for EAAT2a in astrocytic processes (A) and axon terminals (B). Arrows point to several gold particles dispersed in the cytoplasm or associated to membranes. (C-H) Localization of membrane-associated gold particles coding for EAAT2a in astrocytic processes $\mathbf{( C , D )}$ and axon terminals $(\mathbf{F}, \mathbf{G})$ in relation to the AZ-PSD complex of asymmetric synapses. (E,H) Graphs show distance of gold particles detected in astrocytic processes (E) and axon terminals $(\mathbf{F})$ from the $A Z$ edge of terminals forming asymmetric synapses. The $y$-axis indicates the density of particles for each bin $(20 \mathrm{~nm})$, obtained by dividing the number of particles counted in each bin by the number of profiles extending that far. Den, dendrite; AsP, astrocytic process; AxT, axon terminal; $A Z$, active zone; $P S D$, post-synaptic density. Scale bars: $60 \mathrm{~nm}$ for $(\mathbf{A}, \mathbf{B})$; $100 \mathrm{~nm}$ for $(\mathbf{C}, \mathbf{D}, \mathbf{F}, \mathbf{G})$. used and by several confounding factors, i.e., nature of the samples (autoptic vs bioptic), cause of death, postmortem interval (PMI; for autoptic samples), presence of brain diseases, fixative used for tissue preservation (Lewis, 2002). As far as EAAT2 studies are concerned, there is evidence that the presence and nature of pathological processes may be responsible for different patterns of immunoreactivity (Ikematsu et al., 2001; Bjornsen et al., 2007); since we did not detect any appreciable abnormality in Nissl and GFAP-stained sections, 
these factors do not seem to apply to our material. Instead, it is worth noting that the "irregular pattern" is described in studies in which either autoptic samples with long PMI (Milton et al., 1997; Fray et al., 1998; Proper et al., 2002; Furuta et al., 2005; Matute et al., 2005) or different antibodies (Milton et al., 1997; Fray et al., 1998; Proper et al., 2002; Furuta et al., 2005; Williams et al., 2005) were used. Interestingly, Proper et al. (2002) showed in autoptic samples that longer PMI are associated to highly irregular EAAT2 pattern. Since EAAT2 detection is sensitive to fixative agents (Chen et al., 2004; Melone et al., 2009), it is likely that long storage of samples in formalin, a common feature of studies using autoptic samples which exerts a masking effect on EAAT2 epitopes, is another important source of variability of EAAT2 immunostaining. The view that the nature of samples and antibodies used are major determinants of differences reported in previous studies of EAAT2 distribution is supported by the observation that two studies reporting a "regular" pattern used the same antibodies used here in autoptic samples with short PMIs (Rothstein et al., 1995; Bar-Peled et al., 1997). In this context, it should be emphasized that we used bioptic material, which permits to fix tissue immediately and thus to rule out an important confounding factor, i.e., PMI. Thus, it appears that use of bioptic material immediately fixed with gentle fixative solutions and conserved in a fixative-free solution and of well-characterized antibodies may have allowed a good preservation of antigenicity and a better detection of EAAT2a-ir in our material.

\section{CELLULAR AND SYNAPTIC LOCALIZATION OF EAAT2a IN HUMAN NEOCORTEX}

The results on the cellular localization show that EAAT2 is highly expressed by astrocytes and that numerous EAAT2a-ir elements are axon terminals, whereas we did not notice EAAT2 ir in oligodendrocytes or microglial cells.

Cellular localization of EAAT2 has been rarely studied at the electron microscopic level in human cortex. Bjornsen et al. (2007) reported that in bioptic human epileptogenic hippocampus EAAT2 was exclusively in astrocytic somata and processes. As described in Results, we showed that $\sim 15 \%$ of all EAAT2 ir processes were neuronal. Procedural differences between their study and the present one concern fixation, as they fixed material with PFA and picric acid and post-fixed it with acrolein, whereas we used PFA only. Studies in rats showed that neuronal EAAT2 is visualized in all experimental conditions in which strong fixatives are avoided (Chen et al., 2004; Melone et al., 2009). It is therefore likely that the difference between the observations of Bjornsen et al. (2007) and ours are accounted for by the different fixative procedure employed. These data are in line with evidence gathered in rats showing that some EAAT2 is expressed by neurons (Chen et al., 2004; Furness et al., 2008; Holmseth et al., 2009; Melone et al., 2009; see also Berger et al., 2005; and de Vivo et al., 2010). Analysis of EM data also revealed a remarkable heterogeneity in the organization of asymmetric synapses expressing EAAT2a, as they showed that at asymmetric synapses expressing EAAT2a the transporter is localized in astrocytic processes located near axon terminals expressing EAAT2a, in axon terminals, and in astrocytic processes located near axon terminals not expressing EAAT2a. The observation that different excitatory synapses have different organizational models of GLT-1-mediated Glu uptake suggests that they may have different functional features.
Post-embedding immunogold electron microscopic studies revealed that the density of membrane-associated EAAT2a molecules in astrocytic processes is about 10 times higher than in axon terminals. Assuming that gold particle density is linearly correlated to the number of functional molecules, the evidence that the density of EAAT2a is higher in astrocytes than in axon terminals forming asymmetric synapses indicates that astrocytic EAAT2a is responsible for the largest fraction of glutamate uptake at cortical synapses. We studied the distribution of gold particles coding for GLT-1a in both astrocytic processes contacting asymmetric synapses and in GLT-1a+ terminals forming asymmetric synapses. These studies showed that in both astrocytic processes and axon terminals most EAAT2a was in a membrane region extending for about 250-300 nm from AZ margin. This membrane region is considered perisynaptic (Lujan et al., 1996; Barthó et al., 2004). Thus, at cortical synapses, the regions of high EAAT2a concentration appear to be largely perisynaptic, whereas the regions of lower concentration are extrasynaptic. The demonstration that a large fraction of neuronal and astrocytic EAAT2a is localized at perisynaptic sites parallels our previous findings in rats (Melone et al., 2009). Perisynaptic sites are well suited for modulating the concentration of glutamate in the cleft, as suggested by the observation that in most experimental paradigms antagonizing glutamate transporters enhances synaptic currents (Tzingounis and Wadiche, 2007), and for regulating the amount of glutamate allowed to reach presynaptic receptors (e.g., Omrani et al., 2009). Both mechanisms may contribute to modulating synaptic strength.

Several laboratories have reported the expression of glutamate transporters by oligodendrocytes and microglial cells. Although inconsistencies do exist, results of rodent studies indicate that EAAC1 (EAAT3) is the main oligodendrocytic glutamate transporter, and that GLT-1 (EAAT2) is expressed more robustly during development or in juvenile brains (Domercq et al., 1999; Matute et al., 2007; Desilva et al., 2009). As far as human cerebral cortex is concerned, Desilva et al. (2007) reported that EAAT2 was highly expressed in fetal white matter oligodendrocytes and during early development and virtually disappeared by two postnatal months. The results of our studies are in line with the findings of Desilva et al. (2007). Even considering the resolution limits of immunocytochemical techniques, these data indicate that EAAT2 is either poor or totally absent in human neocortical oligodendrocytes, suggesting that the proposed role of glutamate transport alterations in multiple sclerosis and other demyelinating diseases (Pitt et al., 2003; Matute et al., 2007) is either mediated by glutamate transporters other than EAAT2 or that EAAT2 expression is re-activated in adulthood. The lack of EAAT2a-ir in microglial cells reported here is in line with the notion that in these cells expression of glutamate transporters, including EAAT2, is normally activation-dependent and associated to factors generated during pathological events in the brain (Chrétien et al., 2002; Persson et al., 2005, 2009; Bonifati and Kishore, 2007; Tilleux and Hermans, 2007).

\section{OF RATS AND MEN: COMPARATIVE ANALYSIS OF EAAT2a DISTRIBUTION AND SOME IMPLICATIONS}

We have recently studied the cellular and synaptic localization of EAAT2a (GLT-1a) in the neocortex of rats (Melone et al., 2009). We found that in optimal conditions: (1) 25\% GLT-1a+ profiles 
were axon terminals; (2) $\sim 50 \%$ of GLT-1a+ profiles were in the vicinity of asymmetric synapses; (3) $~ 70 \%$ of GLT-1a located in the vicinity of asymmetric synapses was astrocytic and $\sim 30 \%$ was neuronal; (4) the density of gold particles coding for GLT-1a was much higher in astrocytic processes than in axon terminals; and (5) in both astrocytic processes and axon terminals most gold particles were localized in a membrane region extending for about $250 \mathrm{~nm}$ from active zone margin, with a peak at $140 \mathrm{~nm}$ for astrocytic processes and at 80 for axon terminals. The present findings indicate that in human cortex the distribution and localization of EAAT2a are similar to those of rats. Although little is known on the function of EAAT2a-mediated glutamate uptake in human cortex and on its regulation, available evidence seems to indicate that most functional attributes are similar to those described in mice and rats (Danbolt, 2001). Thus, the distribution, localization and function of EAAT2a appears virtually identical in both species.

This conclusion impinges upon two issues of considerable importance in contemporary neurosciences. First, thousands of articles and books have been written on the specialization of human

\section{REFERENCES}

Alonso-Nanclares, L., Minelli, A., Melone, M., Edwards, R. H., DeFelipe, J., and Conti, F. (2004). Perisomatic glutamatergic axon terminals: a novel feature of cortical synaptology revealed by vesicular glutamate transporter 1 immunostaining. Neuroscience 123, 547-556.

Arriza, J. L., Fairman, W. A., Wadiche, J. I., Murdoch, G. H., Kavanaugh, M. P., and Amara, S. G. (1994). Functional comparisons of three glutamate transporter subtypes cloned from human motor cortex. J. Neurosci. 14, 5559-5569.

Bar-Peled, O., Ben-Hur, H., Biegon, A., Groner,Y., Dewhurst, S., Furuta,A., and Rothstein, J. D. (1997). Distribution of glutamate transporter subtypes during human brain development. J. Neurochem. 69, 2571-2580.

Barthó, P., Payne, J. A., Freund, T. F., and Acsády, L. (2004). Differential distribution of the $\mathrm{KCl}$ cotransporter $\mathrm{KCC} 2$ in thalamic relay and reticular nuclei. Eur. J. Neurosci. 20, 965-975.

Beart, P. M., and O'Shea, R. D. (2007). Transporters for L-glutamate: an update on their molecular pharmacology and pathological involvement. $B r$. J. Pharmacol. 150, 5-17.

Berger, U. V., DeSilva, T. M., Chen, W., and Rosenberg, P. A. (2005). Cellular and subcellular mRNA localization of glutamate transporter isoforms GLT1a and GLT1b in rat brain by in situ hybridization. J. Comp. Neurol. 492, 78-89.

Bjornsen, L. P., Eid, T., Holmseth, S., Danbolt, N. C., Spencer, D. D., and de Lanerolle, N. C. (2007). Changes in glial glutamate transporters in human epileptogenic hippocampus: inadequate explanation for high extracellular glutamate during seizures. Neurobiol. Dis. 25, 319-330.

Bonifati, D. M., and Kishore, U. (2007). Role of complement in neurodegeneration and neuroinflammation. Mol. Immunol. 44, 999-1010.

Bradford, M. M. (1976). A rapid and sensitive method for the quantitation of microgram quantities of protein utilizing the principle of protein-dye binding. Anal. Biochem. 72, 248-254.

Bragina, L., Melone, M., Fattorini, G., Torres-Ramos, M., VallejoIllarramendi, A., Matute, C., and Conti, F. (2006). GLT-1 down-regulation induced by clozapine in rat frontal cortex is associated with synaptophysin up-regulation. J. Neurochem. 99, 134-141.

Brodmann, K. (1909). Vergleichende Lokalisationslehre des Grosshirnrinde in ihren Prinzipien dargestellt auf Grund des Zellenbaues (Translated and edited by L. J. Garey. Localization in the Cerebral Cortex. London: SmithGordon, 1994). Leipzig: Barth Verlag.

Chen, W., Mahadomrongkul, V., Berger, U. V., Bassan, M., DeSilva, T., Tanaka, K., Irwin, N., Aoki, C., and Rosenberg, P. A. (2004). The glutamate transporter GLTla is expressed in excitatory axon terminals of mature hippocampal neurons. J. Neurosci. 24, 1136-1148.

Chrétien, F., Vallat-Decouvelaere, A. V., Bossuet, C., Rimaniol, A. C., Le Grand, R., LePavec, G., Créminon, C., Dormont, D., Gray, F., and Gras, G. (2002). Expression of excitatory amino acid transporter-2 (EAAT-2) and glutamine synthetase (GS) in brain macrophages and microglia

cerebral cortex, and the theme is still far from being clarified. A large body of comparative studies has evidenced both similarities and differences (e.g., Dehaene et al., 2005; Kaas and Preuss, 2007; Passingham, 2008) and it is not clear how to capture them. In this context, our data add the observation that the major high-affinity plasma membrane transport system for the transmitter released at the majority of cortical synapses, including cortico-cortical synapses, is similar in rats and humans. Second, usefulness of animal models of human neuropsychiatric diseases is often questioned, based on the view that anatomical, chemical and functional features of animals used in such studies, usually rats, differ from those of human brains. As the present observations showed that the distribution and localization of EAAT2a are virtually identical in rats and humans, they also indicate that animal models aimed at defining the role of EAAT2a may be of significant help in our understanding of the pathophysiology of numerous neuropsychiatric diseases of great clinical relevance.

\section{ACKNOWLEDGMENTS}

Supported by MIUR and Università Politecnica delle Marche.

of SIVmac251-infected macaques. Neuropathol. Appl. Neurobiol. 28, 410-417.

Clarke, S., and Miklossy, J. (1990). Occipital cortex in man: organization of callosal connections, related myeloand cytoarchitecture, and putative boundaries of functional visual areas. J. Comp. Neurol. 298, 188-214.

Conti, F., Barbaresi, P., Melone, M., and Ducati, A. (1999). Neuronal and glial localization of NR1 and NR2A/B subunits of the NMDA receptor in the human cerebral cortex. Cereb. Cortex $9,110-120$.

Conti, F., and Hicks, T. P. (eds). (1996). Excitatory Amino Acids and the Cerebral Cortex. Cambridge, MA: MIT Press.

Conti, F., Melone, M., DeBiasi, S., Minelli, A., Brecha, N.C., and Ducati,A. (1998). Neuronal and glial localization of GAT-1, a high affinity g-aminobutyric acid plasma membrane transporter, in human cerebral cortex; with a note on its distribution in monkey cortex. $J$. Comp. Neurol. 396, 51-63.

Conti, F., and Weinberg, R. J. (1999). Shaping excitation at glutamatergic synapses. Trends Neurosci. 22, 451-458.

Danbolt, N. C. (2001). Glutamate uptake. Prog. Neurobiol. 65, 1-105.

Danbolt, N. C., Pines, G., and Kanner, B. I. (1990). Purification and reconstitution of the sodium- and potassium-coupled glutamate transport glycoprotein from rat brain. Biochemistry 29 6734-6740.

Danbolt, N. C., Storm-Mathisen, J., and Kanner, B. I. (1992). An [Na+-K+] coupled L-glutamate transporter purified from rat brain is located in glial cell processes. Neuroscience 51 295-310.

Dehaene, S., Duhamel, J.-R., Hauser, M. D., and Rizzolatti, G. (2005). From Monkey Brain to Human Brain. Cambridge, MA: MIT Press.

Desilva, T. M., Kabakov, A. Y., Goldhoff, P. E., Volpe, J. J., and Rosenberg, P. A. (2009). Regulation of glutamate transport in developing rat oligodendrocytes. J. Neurosci. 29, 7898-7908.

Desilva, T. M., Kinney, H. C., Borenstein, N. S., Trachtenberg, F. L., Irwin, N., Volpe, J.J., and Rosenberg, P.A. (2007). The glutamate transporter EAAT2 is transiently expressed in developing human cerebral white matter. J. Comp. Neurol. 501, 879-890.

de Vivo, L., Melone, M., Rothstein, J. D., and Conti, F. (2010). GLT-1 promoter activity in astrocytes and neurons of mouse hippocampus and somatic sensory cortex. Front. Neuroanat. 3:31. doi: 10.3389/neuro.05.031.2009

Domercq, M., Sánchez-Gómez, M. V., Areso, P., and Matute, C. (1999). Expression of glutamate transporters in rat optic nerve oligodendrocytes. Eur. J. Neurosci. 11, 2226-2236.

Fray, A. E., Ince, P. G., Banner, S. J., Milton, I. D., Usher, P. A., Cookson, M. R., and Shaw, P. J. (1998). The expression of the glial glutamate transporter protein EAAT2 in motor neuron disease: an immunohistochemical study. Eur. J. Neurosci. 10, 2481-2490.

Fritschy, J. M. (2008). Is my antibodystaining specific? How to deal with pitfalls of immunohistochemistry. Eur. J. Neurosci. 28, 2365-2370.

Furness, D. N., Dehnes, Y., Akhtar, A. Q. Rossi, D. J., Hamann, M., Grutle, N. J., Gundersen, V., Holmseth, S., Lehre, 
K. P., Ullensvang, K., Wojewodzic, M., Zhou, Y., Attwell, D., and Danbolt, N. C. (2008). A quantitative assessment of glutamate uptake into hippocampal synaptic terminals and astrocytes: new insights into a neuronal role for excitatory amino acid transporter 2 (EAAT2). Neuroscience 157, 80-94.

Furuta, A., Takashima, S., Yokoo, H., Rothstein, J. D., Wada, K., and Iwaki, T. (2005). Expression of glutamate transporter subtypes during normal human corticogenesis and type II lissencephaly. Brain Res. Dev. Brain Res. 155, 155-164.

Hansen, L. A., Armstrong, D. M., and Terry, R. D. (1987). An immunohistochemical quantification of fibrous astrocytes in the aging human cerebral cortex. Neurobiol. Aging 8, 1-6.

Holmseth, S., Ha, S., Real, K., Lehre, K. P., Leergaard, T. B., Bjaalie, J. G., and Danbolt, N. C. (2009). The concentrations and distributions of three C-terminal variants of the GLT1 (EAAT2; slc1a2) glutamate transporter protein in rat brain tissue suggest differential regulation. Neuroscience 162, 1055-1071.

Ikematsu, K., Tsuda, R., Orihara, Y., and Nakasono, I. (2001). The expression of excitatory amino acid transporter 2 (EAAT2) in forensic autopsy cases. Forensic Sci. Int. 118, 49-55.

Kaas, J., and Preuss, T. M. (eds). (2007). Evolution of Nervous Systems: A Comprehensive Reference. New York, NY: Academic Press.

Kanai, Y., and Hediger, M. A. (2004). The glutamate/neutral amino acid transporter family SLC1: molecular, physiological and pharmacological aspects. Pflugers Arch. 447, 469-479.

Katagiri, H., Tanaka, K., and Manabe, T. (2001). Requirement of appropriate glutamate concentrations in the synaptic cleft for hippocampal LTP induction. Eur. J. Neurosci. 14, 547-553.

Kharazia, V. N., and Weinberg, R. J. (1997). Tangential synaptic distribution of NMDA and AMPA receptors in rat neocortex. Neurosci. Lett. 238, $41-44$.

Lauriat, T. L., and McInnes, L. A. (2007). EAAT2 regulation and splicing: relevance to psychiatric and neurological disorders. Mol. Psychiatry 12, 1065-1078.

Lehre, K. P., Levy, L. M., Ottersen, O. P., Storm-Mathisen, J., and Danbolt, N. C. (1995). Differential expression of two glial glutamate transporters in the rat brain: quantitative and immunocytochemical observations. J. Neurosci. 15, 1835-1853.

Levenson, J., Weeber, E., Selcher, J. C., Kategaya, L. S., Sweatt, J.D., and Eskin, A. (2002). Long-term potentiation and contextual fear conditioning increase neuronal glutamate uptake. Nat. Neurosci. 5, 155-161.

Levy, L. M., Lehre, K. P., Rolstad, B., and Danbolt, N. C. (1993). A monoclonal antibody raised against an $\left[\mathrm{Na}^{+}-\mathrm{K}^{+}\right]$ coupled L-glutamate transporter purified from rat brain confirms glial cell localization. FEBS Lett. 317, 79-84.

Lewis, D. A. (2002). The human brain revisited: opportunities and challenges in postmortem studies of psychiatric disorders. Neuropsychopharmacology 26, 143-154.

Lujan, R., Nusser, Z., Roberts, J. D., Shigemoto, R., and Somogyi, P. (1996). Perisynaptic location of metabotropic glutamate receptors mGluR1 and mGluR5 on dendrites and dendritic spines in the rat hippocampus. Eur. J. Neurosci. 8, 1488-1500.

Marco, P., Sola, R. G., Pulido, P., Alijarde,M. T., Sanchez, A., Ramon y Cajal, S., and DeFelipe, J. (1996). Inhibitory neurons in the human epileptogenic temporal neocortex. An immunocytochemical study. Brain 119, 1327-1347.

Matute, C., Alberdi, E., Domercq, M., Sánchez-Gómez, M. V., PérezSamartín, A., Rodríguez-Antigüedad, A., and Pérez-Cerdá, F. (2007). Excitotoxic damage to white matter. $J$. Anat. 210, 693-702.

Matute, C., Melone, M., VallejoIllarramendi, A., and Conti, F. (2005). Increased expression of the astrocytic glutamate transporter GLT-1 in the prefrontal cortex of schizophrenics. Glia 49, 451-455.

Melone, M., Barbaresi, P., Fattorini, G., and Conti, F. (2005a). Localization of the GABA plasma membrane transporter GAT-3 in human cerebral cortex: a procedural artifact? J. Chem. Neuroanat. 30, 45-54.

Melone, M., Burette, A., and Weinberg, R. J. (2005b). Light microscopic identification and immunocytochemical characterization of glutamatergic synapses in brain sections. J. Comp. Neurol. 28, 495-509.

Melone, M., Bellesi, M., and Conti, F. (2009). Synaptic localization of GLT-1a in the rat somatic sensory cortex. Glia 57, 108-117.

Melone, M., Quagliano, F., Barbaresi, P., Varoqui, H., Erickson, J. D., and Conti, F. (2004). Localization of the glutamine transporter SNAT1 in rat cerebral cortex and neighboring structures, with a note on its localization in human cortex. Cereb. Cortex 14, 562-574.

Melone, M., Varoqui, H., Erickson, J. D., and Conti, F. (2006). Localization of the $\mathrm{Na}^{+}$-coupled neutral amino acid transporter 2 in the cerebral cortex. Neuroscience 140, 281-292.

Milton, I. D., Banner, S. J., Ince, P. G., Piggott, N. H., Fray, A. E., Thatcher,
N., Horne, C. H., and Shaw, P. J. (1997). Expression of the glial glutamate transporter EAAT2 in the human CNS: an immunohistochemical study. Brain Res. Mol. Brain Res. 52, 17-31.

Minelli, A., Barbaresi, P., Reimer, R. J., Edwards, R. H., and Conti, F. (2001). The glial glutamate transporter GLT-1 is localized both in the vicinity of and at distance from axon terminals in the rat cerebral cortex. Neuroscience 108, 151-159.

Omrani, A., Melone, M., Bellesi, M., Safiulina, V., Aida, T., Tanaka, K., Cherubini, E., and Conti, F. (2009). Up-regulation of GLT-1 severely impairs LTD at mossy fibre-CA3 synapses. J. Physiol. 587, 4575-4588.

Ong, W. Y., and Garey, L. J. (1990). Neuronal architecture in the human temporal cortex. Anat. Embryol. 181, 351-364.

Passingham, R. (2008). What is Special About Human Brain? Oxford: Oxford University Press.

Persson, M., Brantefjord, M., Hansson, E., and Rönnbäck, L. (2005). Lipopolysaccharide increases microglial GLT-1 expression and glutamate uptake capacity in vitro by a mechanism dependent on TNF-alpha. Glia 51, 111-120.

Persson, M., Pekna, M., Hansson, E., and Rönnbäck, L. (2009). The complement-derived anaphylatoxin C5a increases microglial GLT-1 expression and glutamate uptake in a TNF-alpha-independent manner. Eur. J. Neurosci. 29, 267-274.

Peters, A., Palay, S. L., and Webster H. D. (1991). The Fine Structure of the Nervous System. Neurons and their Supportive Cells. New York: Oxford University Press.

Phend, K. D., Rustioni, A., and Weinberg, R. J. (1995). An osmium-free method of epon embedment that preserves both ultrastructure and antigenicity for post-embedding immunocytochemistry. J. Histochem. Cytochem. 43, 283-292.

Phend, K. D., Weinberg, R. J., and Rustioni, A. (1992). Techniques to optimize post-embedding single and double staining for amino acid neurotransmitters. J. Histochem. Cytochem. 40, 1011-1020.

Pines, G., Danbolt, N. C., Bjørås, M., Zhang, Y., Bendahan, A., Eide, L., Koepsell, H., Storm-Mathisen, J., Seeberg, E., and Kanner, B. I. (1992). Cloning and expression of a rat brain L-glutamate transporter. Nature 360 , 464-467.

Pitt, D., Nagelmeier, I. E., Wilson, H. C., and Raine, C. S. (2003). Glutamate uptake by oligodendrocytes: implications for excitotoxicity in multiple sclerosis. Neurology 61, 1113-1120.
Proper, E. A., Hoogland, G., Kappen, S. M., Jansen, G. H., Rensen, M. G., Schrama, L. H., van Veelen, C. W., van Rijen, P. C., van Nieuwenhuizen, O., Gispen, W. H., and de Graan, P. N. (2002). Distribution of glutamate transporters in the hippocampus of patients with pharmaco-resistant temporal lobe epilepsy. Brain 125, 32-43.

Racz, B., and Weinberg, R. J. (2004). The subcellular organization of cortactin in hippocampus. J. Neurosci. 24, 10310-10317.

Rajkowska, G., and Goldman-Rakic, P. S. (1995). Cytoarchitectonic definition of prefrontal areas in the normal human cortex: I. Remapping of areas 9 and 46 using quantitative criteria. Cereb. Cortex 5, 307-322.

Rothstein, J. D. (2009). Current hypotheses for the underlying biology of amyotrophic lateral sclerosis. Ann. Neurol. 65(Suppl. 1), S3-S9.

Rothstein, J. D., Dykes-Hoberg, M., Pardo, C. A., Bristol, L. A., Jin, L., Kuncl, R. W., Kanai, Y., Hediger, M. A., Wang, Y., Schielke, J. P., and Welty, D. F. (1996). Knockout of glutamate transporters reveals a major role for astroglial transport in excitotoxicity and clearance of glutamate. Neuron 16, 675-686.

Rothstein, J. D., Martin, L., Levey, A. I., Dykes-Hoberg, M., Jin, L., Wu, D., Nash, N., and Kuncl, R. W. (1994). Localization of neuronal and glial glutamate transporters. Neuron 13 , 713-725.

Rothstein, J. D., Van Kammen, M., Levey, A. I., Martin, L. J., and Kuncl, R. W. (1995). Selective loss of glial glutamate transporter GLT-1 in amyotrophic lateral sclerosis. Ann. Neurol. 38, 73-84.

Rusakov, D. A., Kullmann, D. M., and Stewart, M. G. (1999). Hippocampal synapses: do they talk to their neighbours? Trends Neurosci. 22, 382-388.

Saper, C. B., and Sawchenko, P. E. (2003). Magic peptides, magic antibodies: guidelines for appropriate controls for immunohistochemistry. J. Comp. Neurol. 465, 161-163.

Scheperjans, F., Hermann, K., Eickhoff, S. B., Amunts, K., Schleicher, A. and Zilles, K. (2008). Observerindependent cytoarchitectonic mapping of the human superior parietal cortex. Cereb. Cortex 18, 846-867.

Semendeferi, K., Armstrong,E.,Schleicher, A., Zilles, K., and Van Hoesen, G. W. (2001). Prefrontal cortex in humans and apes: a comparative study of area 10. Am. J. Phys. Anthropol. 114 224-241.

Sheldon, A.L., and Robinson, M. B. (2007). The role of glutamate transporters in neurodegenerative diseases and 
potential opportunities for intervention. Neurochem. Int. 51, 333-355.

Tanaka, K., Watase, K., Manabe, T., Yamada, K., Watanabe, M., Takahashi, K, Iwama, H., Nishikawa, T., Ichihara, N., Kikuchi, T., Okuyama, S., Kawashima, N., Hori, S., Takimoto, M., and Wada, K. (1997). Epilepsy and exacerbation of braininjury in micelacking the glutamate transporter GLT-1. Science 276, 1699-1702.

Tilleux, S., and Hermans, E. (2007). Neuroinflammation and regulation of glial glutamate uptake in neurological disorders. J. Neurosci. Res. 85, 2059-2070.

Torp, R., Danbolt, N. C., Babaie, E., Bjoras, M., Seeberg, E., Storm-Mathisen, J., and Ottersen, O. P. (1994). Differential expression of two glial glutamate transporters in the rat brain: an in situ hybridization study. Eur. J. Neurosci. 6, 936-942.

Torres, G. E., and Amara, S. G. (2007). Glutamate and monoamine transporters: new visions of form and function. Curr. Opin. Neurobiol. 17, 304-312.

Tyler, W. J., and Pozzo-Miller, L. D (2001). BDNF enhances quantal neurotransmitter release and increases the number of docked vesicles at the active zones of hippocampal excitatory synapses. J. Neurosci. 21, 4249-4258.

Tzingounis, A. V., and Wadiche, J. I. (2007). Glutamate transporters: confining runaway excitation by shaping synaptic transmission. Nat. Rev. Neurosci. 8, 935-947.

Valtschanoff, J. G., and Weinberg, R. J. (2001). Laminar organization of the NMDA receptor complex within the postsynaptic density. J. Neurosci. 21, 1211-1217.

Vogt, B. A., Nimchinsky, E. A., Vogt, L. J., and Hof, P. R. (1995). Human cingulate cortex: surface features, flat maps, and cytoarchitecture. J. Comp. Neurol. 359, 490-506.

von Economo, C. (1928). La citoarchitettonica della Corteccia Cerebrale. Bologna: Cappelli.

Williams, S. M., Sullivan, R. K., Scott, H. L., Finkelstein,D.I.,Colditz,P.B.,Lingwood, B. E., Dodd, P. R., and Pow, D. V. (2005). Glial glutamate transporter expression patterns in brains from multiple mammalian species. Glia 49, 520-541.

Conflict of Interest Statement: The authors declare that the research was conducted in the absence of any commercial or financial relationships that could be construed as a potential conflict of interest.

Received: 01 December 2010; paper pending published: 23 December 2010; accepted: 24 December 2010; published online: 14 January 2011.

Citation: Melone M, Bellesi M, Ducati A, Iacoangeli $M$ and Conti F (2011) Cellular and synaptic localization of EAAT2a in human cerebral cortex. Front. Neuroanat. 4:151. doi: 10.3389/fnana.2010.00151 Copyright (c) 2011 Melone, Bellesi, Ducati, Iacoangeli and Conti. This is an open-access article subject to an exclusive license agreement between the authors and the Frontiers Research Foundation, which permits unrestricted use, distribution, and reproduction in any medium, provided the original authors and source are credited. 